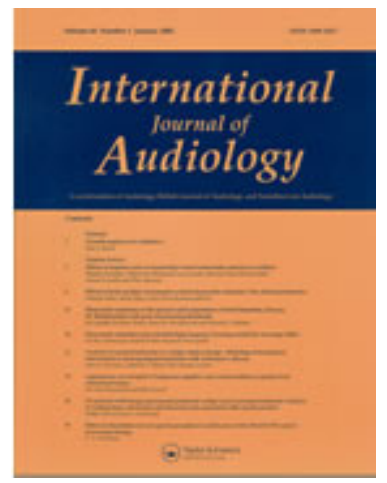

\title{
Cancer survivors treated with platinum-based chemotherapy affected by ototoxicity and the impact on quality of life: a narrative synthesis systematic review.
}

\begin{tabular}{|r|l|}
\hline Journal: & International Journal of Audiology \\
\hline Manuscript ID & TIJA-2019-07-0257.R1 \\
\hline Danuscript Type: & Review Paper \\
\hline Author: & $19-$ Aug-2019 \\
\hline Komplete List of Authors: & $\begin{array}{l}\text { Pearson, Stephanie; University of Nottingham, Hearing Sciences, } \\
\text { Division of Clinical Neuroscience; NIHR Nottingham Biomedical Research } \\
\text { Centre, Ropewalk House } \\
\text { Taylor, John; University of Nottingham, NIHR Nottingham Hearing } \\
\text { Biomedical Research Centre, Hearing Sciences, Division of Clinical } \\
\text { Neuroscience, School of Medicine; National Institutes for Health Research } \\
\text { Nottingham, Hearing Sciences } \\
\text { Patel, Poulam; Nottingham University Hospitals NHS Trust, Academic } \\
\text { Unit of Oncology; University of Nottingham School of Medicine, Academic } \\
\text { Unit of Oncology } \\
\text { Baguley, David; National Institutes for Health Research Nottingham, } \\
\text { Hearing Sciences; NIHR Nottingham Biomedical Research Centre, } \\
\text { Ropewalk House; Nottingham University Hospitals NHS Trust, Ropewalk } \\
\text { House }\end{array}$ \\
\hline Keywords: & $\begin{array}{l}\text { Tinnitus, Psycho-social/Emotional, Conditions/Pathology/Disorders, Adult } \\
\text { or General Hearing Screening }\end{array}$ \\
\hline
\end{tabular}

\section{SCHOLARONE Manuscripts}




\section{Cancer survivors treated with platinum-based chemotherapy affected by ototoxicity and the impact on quality of life: a narrative synthesis systematic review.}

Stephanie E. Pearson ${ }^{\mathrm{a}, \mathrm{b} *}$, John Taylor ${ }^{\mathrm{a}, \mathrm{b}}$, Poulam Patel ${ }^{\mathrm{c}, \mathrm{d}}$ and David M.

Baguley $y^{\mathrm{a}, \mathrm{b}, \mathrm{c}}$

${ }^{a}$ NIHR Nottingham Biomedical Research Centre, Ropewalk House, 113 The Ropewalk, Nottingham, NG1 5DU; ${ }^{b}$ Hearing Sciences, Division of Clinical Neuroscience, School of Medicine, University of Nottingham, University Park, Nottingham, NG7 2RD; ${ }^{c}$ Nottingham University Hospitals NHS Trust, Hucknall Road, Nottingham, NG5 1PB; 'dAcademic Unit of Oncology, Division of Cancer and Stem Cells, School of Medicine, University of Nottingham Stephanie E. Pearson*

Hearing Sciences,

Building 40

University Park

Nottingham, NG7 2RD

01158232611

stephanie.pearson@nottingham.ac.uk 
Keywords: cancer, platinum based chemotherapy, ototoxicity, hearing, tinnitus, quality of life 
Cancer survivors treated with platinum-based chemotherapy affected by ototoxicity and the impact on quality of life: a narrative systematic review.

Objective: To identify any change in quality of life (QoL) caused by chemotherapy-induced toxicities, such as hearing loss and tinnitus, to provide information in order to improve services and aid clinicians in their decisionmaking.

Design: This systematic review followed the PRISMA checklist. The search terms were cancer, platinum-based chemotherapy, ototoxicity and "quality of life". Titles and abstracts, followed by full texts, were screened by two independent researchers. The relevant data were extracted and quality analysis was performed using the NIH Quality Assessment Tool.

Study Sample: 308 titles and abstracts were screened, and 27 full text articles were screened. Ten articles representing 11 studies were included in the review. Study design included cross-sectional studies, randomised control trials and longitudinal studies.

Results: Diagnostic criteria consisted of audiograms, questionnaires, and patient complaints. The study quality ranged from $21.43 \%$ to $85.71 \%$. Overall results found that those treated with cisplatin had more hearing loss and tinnitus than those treated with other therapies. Furthermore, those with hearing loss and tinnitus were more likely to have a lower QoL.

Conclusions: There is an urgent need to standardise diagnostics when investigating ototoxicity and its effect on QoL, particularly for research into risk factors, prevention and management.

Keywords: cancer, platinum-based chemotherapy, survivorship, ototoxicity, hearing, tinnitus, quality of life 


\section{Introduction}

Cancer continues to be a life-altering diagnosis, however due to medical advances there has been an overall decline of $26 \%$ in cancer deaths within the past two decades (Siegel, Miller, and Jemal 2018). Treatment effects, though, can often cause long-term physical and psychological challenges for survivors (Skalleberg et al. 2017; Alfano and Rowland 2006). For this reason, there is a requirementto look into how these long-term effects impact (QoL) for those who are adapting to a life with and beyond cancer.

Platinum-based chemotherapy is typically used to treat most solid tumours, including breast, testicular and ovarian cancers (Oun, Moussa, and Wheate 2018; Theile and Dirk 2017; Kelland 2007). Due to its cost effective systematic and cytotoxic effects, it has been one of the most efficient and widely available chemotherapies (Paken et al. 2016). However, it is widely known that platinum-based chemotherapycan cause ototoxicity (Campbell and Le Prell 2018; Saladin et al. 2015). Ototoxicity refers to any hearing deficit or tinnitus resulting from a temporary or permanent inner ear dysfunction, following treatment with an ototoxic drug (Paken et al. 2016). Ototoxic drugs include aminoglycoside antibiotics such as gentamicin, loop diuretics such as torasemide and neurologic drugs, such as sodium valproate (Bisht and Bist 2011). Ototoxic effects commonly manifest as tinnitus and/or high frequency hearing loss that can later progress to lower frequencies (Waissbluth, Peleva, and Daniel 2017). Both tinnitus and hearing loss are associated with a higher risk of depression, social isolation, anxiety (Nordvik et al. 2018) and dementia (Gurgel et al. 2014; Deal et al. 2016). It may not be possible to identify the specific time point during treatment at which an effect first appears, making it challenging to determine the causality and risk of each therapy received (Stein, Syrjala, and Andrykowski 2008). For this reason, literature reporting adverse health effects associated with chemotherapy can be imprecise and lacking in detail. 
Furthermore, collating systematic evidence on adverse effects can be difficult. Specific toxicities are rarely included in key words, titles or abstracts. To overcome this challenge, a compromise between sensitivity and precision must be made when performing a systematic search (Golder and Loke 2009).

To date, there have been no systematic reviews carried out exploring the impact on QoL from platinum-based chemotherapy-induced ototoxicity.

\section{Materials and Methods \\ Eligibility Criteria}

The four themes that had to be present in an article were: any mention of cancer, platinumbased chemotherapy, ototoxicity and QoL. Known key articles were checked in the searches to ensure all relevant articles were included in the search. There was no limitation on the date range of this search.

The inclusion criteria consisted of: any combination of treatments which included platinum-based chemotherapy for curative intent, any type of formal QoL assessment, any type of formal hearing loss and/or tinnitus assessment, written in the English language, any study design providing the relevant results were obtained after treatment and any cancer type other than head and neck. Any paediatric study was excluded, in addition to review articles, grey literature and both in vitro and in vivo studies.

\section{Information Sources}

This systematic review was conducted following the Preferred Reporting Items for Systematic Reviews and Meta-Analysis (PRISMA) checklist.

Due to the nature of this systematic review and the difficulties in searching for adverse effects of chemotherapy, specificity and precision were optimised in order to capture the most relevant articles and reduce unrelated articles. The terms used were edited 
accordingly to meet the standards of each search engine.

Search engines used were OVIDSP, NCBI, WebofScience and Cochrane. Databases searched therefore consisted of Medline, Pyschinfo and PyschArticles, Embase, PubMed, WebofScience Core Collection and the Cochrane Database.

\section{Study Selection}

Titles and abstracts were imported to Endnote, duplicates were removed and the remainder were screened by two independent authors (SP and JT) against the eligibility criteria. Any disagreement was resolved by consensus. Full-text articles of potentially relevant papers were also assessed for eligibility, resolving any discrepancies by consensus.

\section{Data Extraction Process}

Determinants such as paper characteristics, type of study design, sample size, patient demographics, and the measurements used and analysed, in addition to the results of the specific study, were all extracted. The information that could be compared across studies was then analysed accordingly, with the remaining information displayed as a description in order to capture the full results.

\section{Risk of Bias in Individual Studies}

A quality assessment was carried out on each of the studies included in this review using a 14-item study quality assessment tool involving pre-defined principles, the NIH's Quality Assessment Tools (“Study Quality Assessment Tools | National Heart, Lung, and Blood Institute (NHLBI)" 2018). An item was scored 1 for matching the criteria, and scored 0 if it was not clear or did not match the criteria. Aggregate percentages were used to classify poorquality $(\leq 50 \%)$, and high-quality $(>50 \%)$ studies. This tool was chosen based on a systematic review carried out by Mols, et.al (Mols et al. 2015). The tool was chosen as it assessed relevant aspects for each study type involved in this review. The-high quality and low-quality studies were grouped, and their results were compared to evaluate consistencies and 
anomalies.

\section{Synthesis of Results}

Due to the heterogeneity of the results reported in this review, it was not possible to statistically combine the results. Therefore, a narrative analysis was carried out, and these descriptive results of each study were compared with one another.

Outcome measures from the studies were extracted and compared, including the diagnostic criteria and grading systems used.

\section{Risk of Bias Across Studies}

The majority of the adverse effects within the studies were not clearly defined, therefore the risk of bias between studies was relatively high. Moreover, not all diagnostic criteria were specified, meaning some studies reported presence of ototoxicity but did not clarify its severity or symptom characteristics, i.e. whether it was hearing loss or tinnitus. The nonrandomised studies were also considered to carry a high risk of bias, as trials without blinding are prone to bias (Loke, Price, and Herxheimer 2007).

\section{Results}

\section{Study Selection}

A total of 645 articles were identified through the database searches performed. From this, 337 articles were excluded due to duplications, grey literature and there being no abstracts available. The resulting 308 titles and abstracts were screened. The screening procedure can be seen inin Figure 1. 


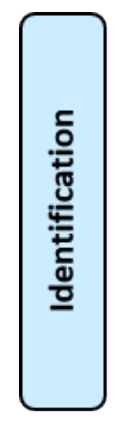

Records identified through database searching $(n=645)$

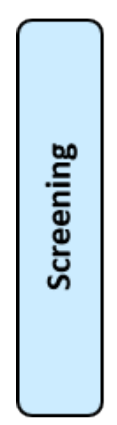

Titles and abstracts screened ( $n=308)$
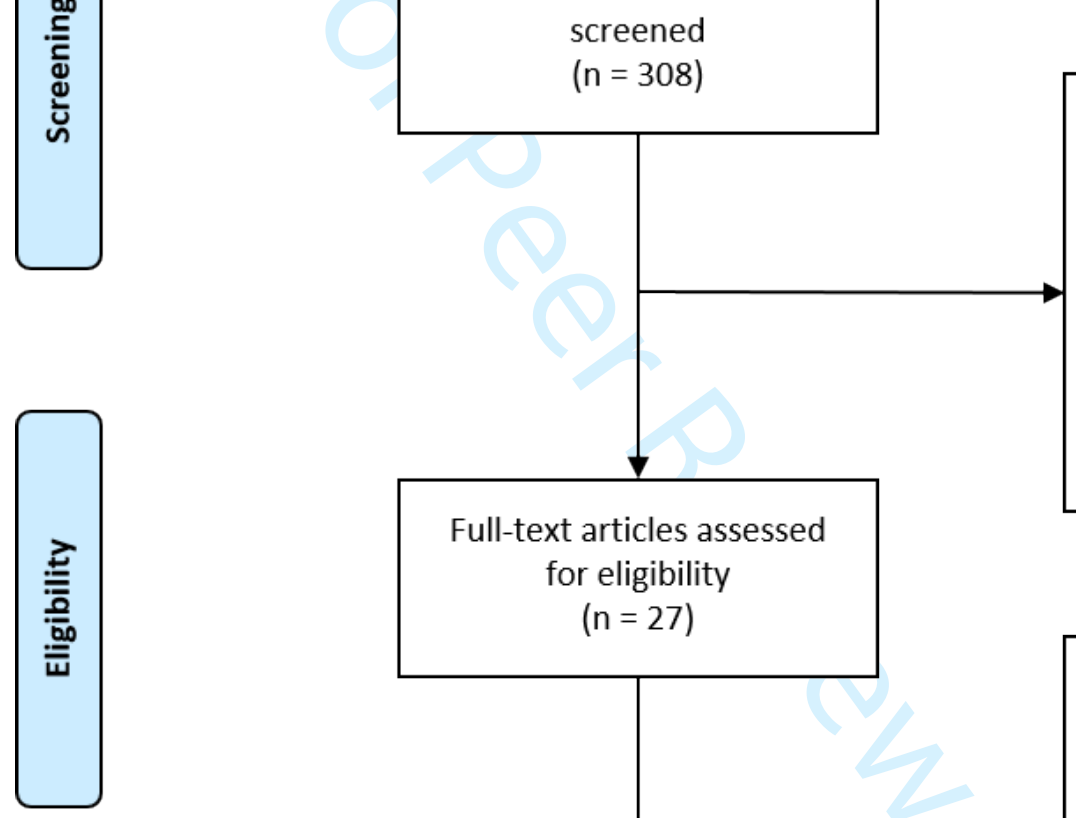

Records excluded $(n=281)$

Duplicates $(n=56)$

No full text $(n=3)$

In vivo studies $(\mathrm{n}=9)$

In vitro studies $(\mathrm{n}=10)$

Paediatric studies $(n=73)$

Grey literature $(n=8)$

Not relevant $(n=73)$

Review article $(n=49)$

$$
\begin{aligned}
& \text { Full-text articles assessed } \\
& \text { for eligibility } \\
& (n=27)
\end{aligned}
$$

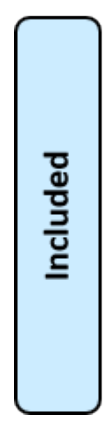

Full-text articles excluded ( $n=17)$

Not English language $(n=1)$

Not relevant to study $(n=6)$ Review ( $n=2)$

Paediatric studies $(n=1)$

Grey Literature $(n=6)$

Palliative care $(n=1)$

Studies included in qualitative synthesis $(n=10)$

Figure 1 displaying the PRISMA flowchart methodology and results obtained for this systematic review. 


\section{Study Characteristics}

The following study characteristics were extracted, as shown in Table 1: location of study, type of study design, population characteristics, number of participants, number of participants treated with platinum-based chemotherapy, diagnostic measurements for ototoxicity, hearing loss, tinnitus and QoL, type of platinum-based chemotherapy, follow-up period, main objective of study and a descriptive summary of the study.

There were six cross-sectional studies included in this systematic review, each with variable timeframes since diagnosis (Bentzen et al. 2013; Bokemeyer et al. 1996; Calhoun et al. 1998; Miaskowski, Paul, Mastick, Schumacher, et al. 2018; Miaskowski, Paul, Mastick, Abrams, et al. 2018; Miaskowski, Mastick, Paul, Abrams, et al. 2018b). In total, 856 participants were included; 565 of these received platinum-based chemotherapy. Two randomised control trials compared cisplatin-based regimens with other types of treatments and included 553 patients, with 313 of these having a platinum-based treatment (Bezjak et al. 2008; Saad, Ghali, and Shawki 2017). Only one longitudinal study was included in this systematic review, following 666 patients with metastatic testicular cancer on two different cisplatin regimens, with 286 (52\%) being followed up at 2 years (Fosså et al. 2003). Finally, one paper involved two separate pilot studies on low-stage testicular cancer survivors from Norway and the UK (Fossa and Fossg 1996). This study involved comparing opinions on toxicities of those treated with infradiaphragmatic radiotherapy, cisplatin, or surveillance and the opinions of a variety of healthcare professionals. From the 309 participants involved, 71 of these received cisplatin.

Most did not report the demographics within each comparison group, but as a whole. For example, the Bentzen, et al. paper describes patient characteristics as $79 \%$ women and $21 \%$ men, with a median age of 61 , and a range of $40-89$ years old for survivors who responded to the survey (Bentzen et al. 2013). Although the information contains those 
treated with cisplatin $(n=56)$, it is not possible to isolate the gender split and age range of this exact subgroup.

Eight of the studies included cisplatin as the platinum-based chemotherapy, and three of the studies carried out by Miaskowskind colleagues do not specify which platinum-based chemotherapy was used (Miaskowski, Paul, Mastick, Abrams, et al. 2018; Miaskowski, Mastick, Paul, Abrams, et al. 2018a; Miaskowski, Paul, Mastick, Schumacher, et al. 2018). Only one study investigated the difference between carboplatin and cisplatin (Saad, Ghali, and Shawki 2017). Moreover, only one study compared the toxicities with those treated with cisplatin to the normal population (Bentzen et al. 2013). 


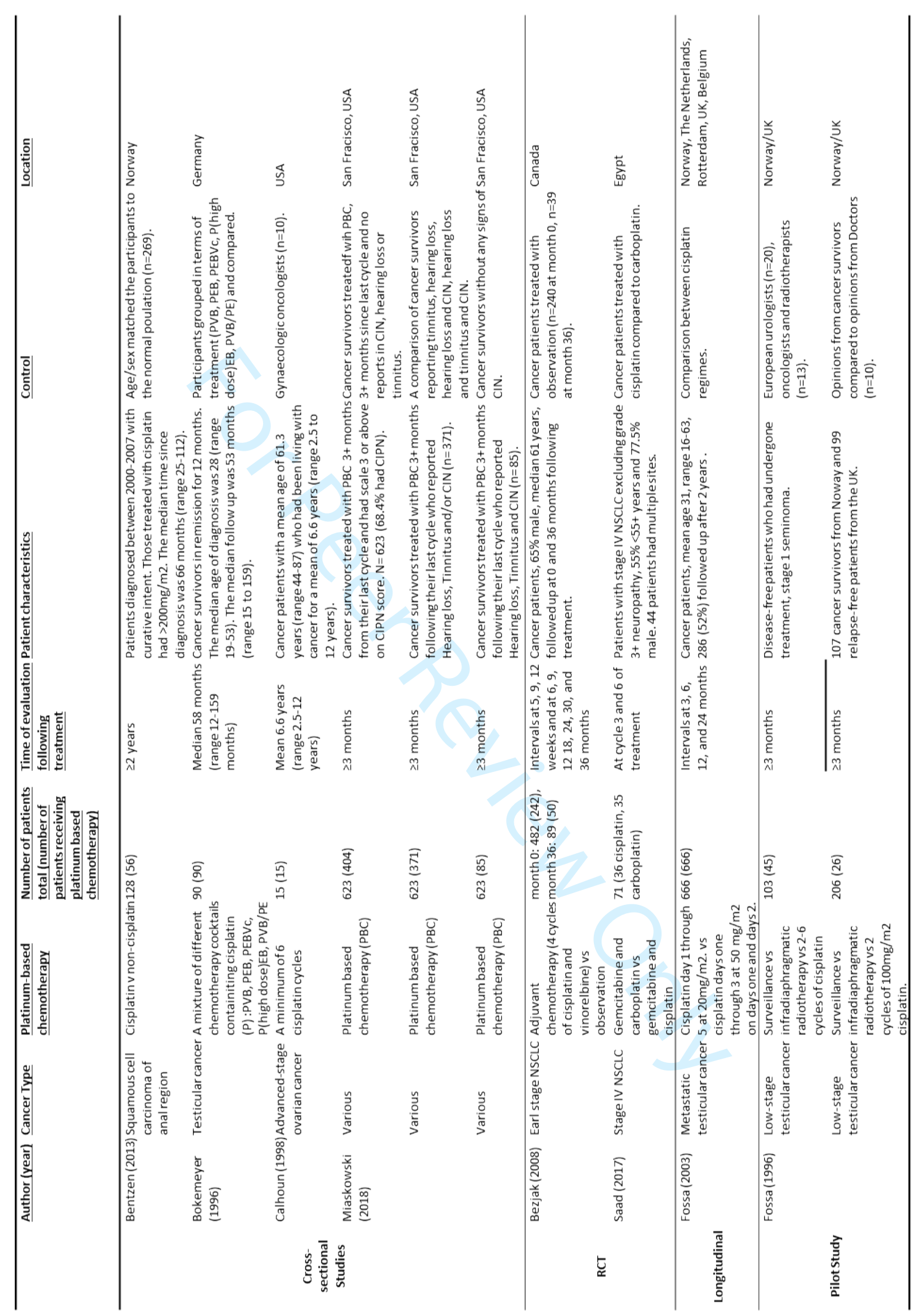

Table 1 displays the study characteristics extracted for this review, including the author, type of study, cancer type, type of platinum-based chemotherapy used, number of participants involved and number of participants involved treated with platinum-based chemotherapy 


\section{Risk of Bias}

The NIH Quality Assessment Tool (“Study Quality Assessment Tools | National Heart, Lung, and Blood Institute (NHLBI)" 2018) was used to assess each of the individual studies. The appraisal criteria involved answering 14 binary questions on the quality of the article. Table 2 displays the quality score for each assessment and the quality percentage calculated, with green being a good-quality study and red being a poor-quality study. Those with a score of $>50 \%(\mathrm{n}=7)$ were classed as a high-quality study, and those $\leq 50 \%(\mathrm{n}=4)$ were classed as a poor-quality study. The studies were grouped according to quality to compare any differences in results and identify any contradicting information.

The papers with a quality score $\leq 50 \%(n=4)$ all compared opinions of patients and healthcare professionals. The papers concluded that most patients perceived the effects of ototoxicity as tolerable, whereas those in health professions perceived the toxicity to affect QoL. However, these studies were all based on hypothetical scenarios and not real life experiences, therefore it could be hypothesised that patients may not realise the extent to which QoL can change when experiencing ototoxicity, compared to professionals. All but one study scoring $>50 \%$ concluded that QoL is indeed affected by tinnitus and/or hearing loss, adding that severity correlated with the dosage and number of cycles. However, one high quality study carried out by Bezjack, et.al. 2008 found no difference in the QoL assessed across different treatments, regardless of experiencing ototoxicity. Yet, this study found that ototoxicity did indeed persist beyond treatment (Bezjak et al. 2008). There were no significant differences in results from the high quality studies compared to the lower quality studies. 


\begin{tabular}{|c|c|c|c|c|c|c|c|c|c|c|c|}
\hline \multirow{2}{*}{$\begin{array}{l}\text { Author (year) } \\
\text { Quality analysis } \\
\end{array}$} & \multirow{2}{*}{$\begin{array}{l}\begin{array}{l}\text { Bentzen } \\
(2013)\end{array} \\
7 / 14\end{array}$} & \multicolumn{2}{|c|}{$\begin{array}{l}\text { Bokemeyer Calhoun } \\
\text { (1996) (1998) }\end{array}$} & \multicolumn{3}{|c|}{ Miaskowski (2018) } & \multirow{2}{*}{\begin{tabular}{|l|}
$\begin{array}{l}\text { Bezjak } \\
\text { (2008) }\end{array}$ \\
$11 / 14$ \\
\end{tabular}} & \multirow{2}{*}{$\begin{array}{l}\begin{array}{l}\text { Saad } \\
(2017)\end{array} \\
9 / 14\end{array}$} & \multirow{2}{*}{$\begin{array}{l}\begin{array}{l}\text { Fossa } \\
(2003)\end{array} \\
12 / 14 \\
\end{array}$} & \multicolumn{2}{|c|}{ Fossa (1996) } \\
\hline & & $9 / 14$ & $7 / 14$ & $10 / 14$ & $10 / 14$ & $9 / 14$ & & & & $3 / 14$ & $3 / 14$ \\
\hline & $.00 \%$ & $64.29 \%$ & $0.00 \%$ & $1.43 \%$ & $71.43 \%$ & $64.29 \%$ & $78.57 \%$ & $64.29 \%$ & $85.71 \%$ & $21.43 \%$ & $21.43 \%$ \\
\hline
\end{tabular}

Table 2 displays the study and the critical appraisal score for each study, using the NIH Quality Assessment Tool. 


\section{Results of the Individual Studies}

0

11

12

13

14

15

16

17

18

19

20

21

22

23

24

25

26

27

28

29

30

31

32

33

34

35

36

37

38

39

40

41

42

43

44

45

46

47

48

49

50

51

52

53

54

55

56

57

58

59

60 


\section{The data extracted in}

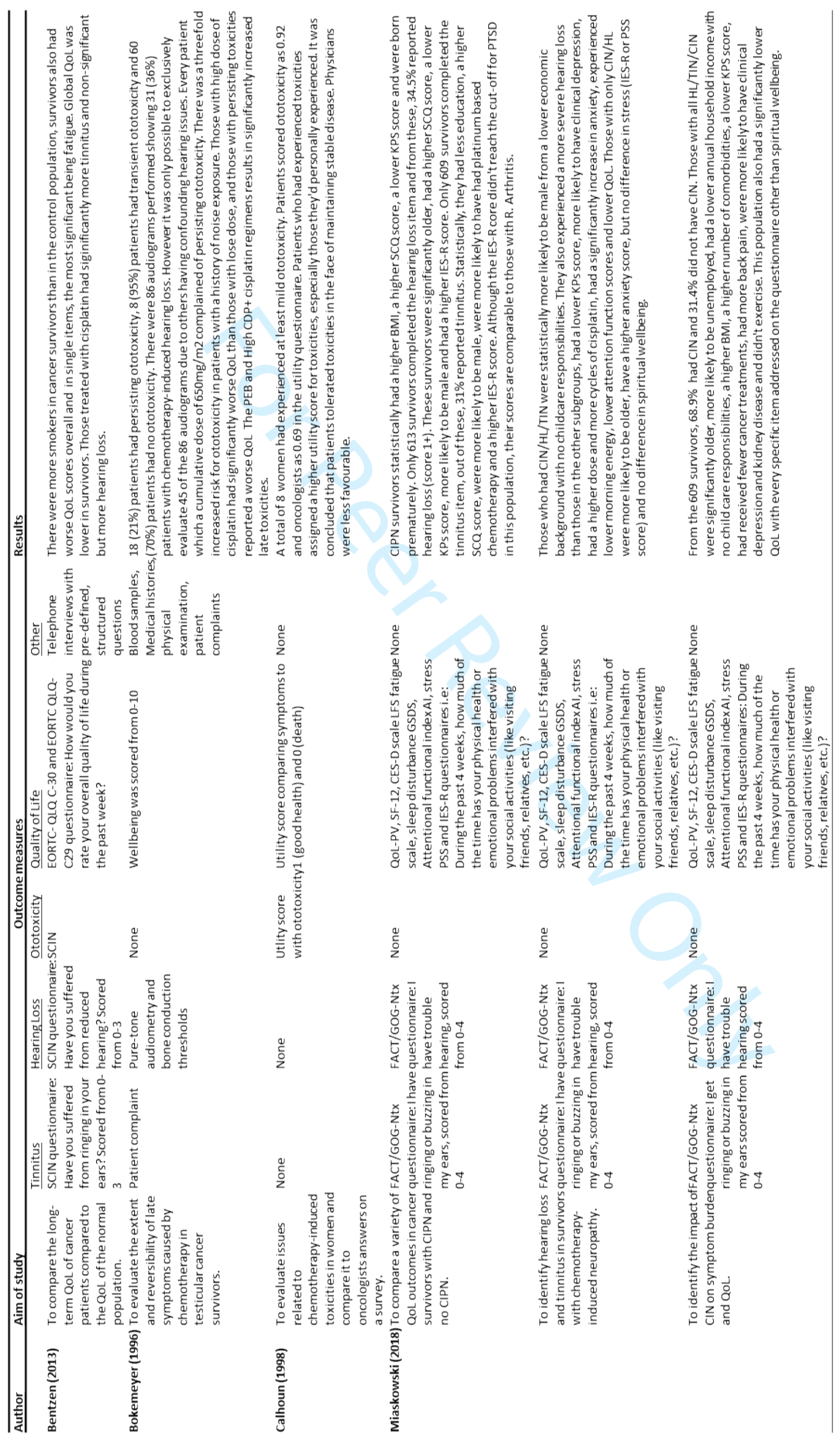


Table 3 demonstrates that there is no standardised outcome measurement used to assess ototoxicity. For example, many of the measurements used in the study analysed ototoxicity, yet did not specify or define ototoxicity. These studies could have measured either hearing loss or tinnitus. Furthermore, many studies did not consider the severity or grading of ototoxicity. One study did, however, perform pure tone audiometry with bone conduction thresholds on patients to assess the extent of their hearing loss (Bokemeyer et al. 1998). The studies carried out by Miaskowski assessed 8 aspects of QoL in addition to a questionnaire identifying the severity of hearing loss and the severity of tinnitus as separate items. Tinnitus was defined as "ringing or buzzing in the ears" (Miaskowski, Paul, Mastick, Schumacher, et al. 2018; Miaskowski, Mastick, Paul, Abrams, et al. 2018a; Miaskowski, Paul, Mastick, Abrams, et al. 2018). The studies compared those with hearing loss, tinnitus and neuropathy to those with just one of the toxicities and those with no toxicities. However, these studies do not report which platinum-based chemotherapy was used, the regimen used, 
the dosage or how many cycles each patient received.

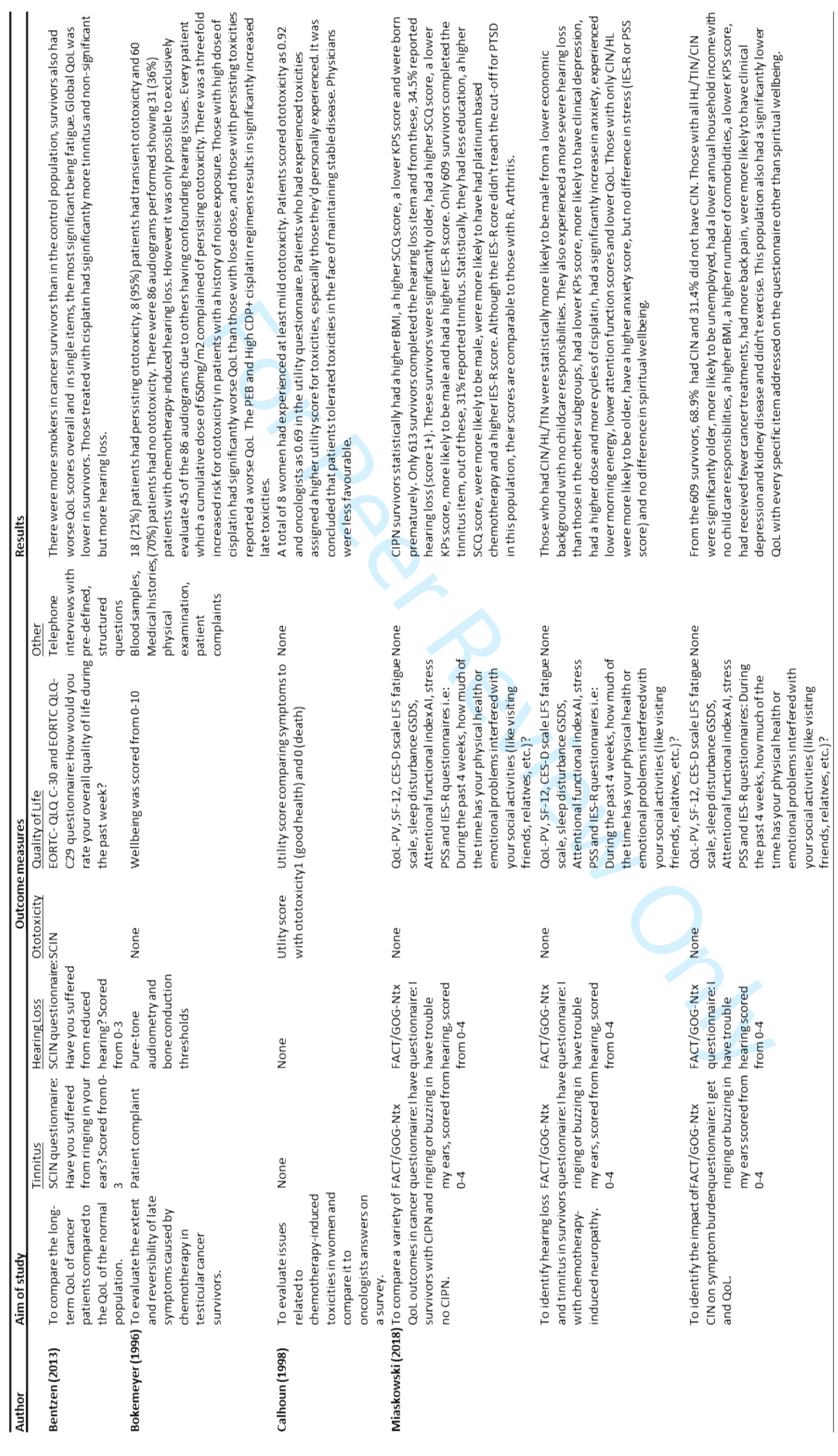


Table 3 displays the results extracted from the individual studies in the systematic review. 


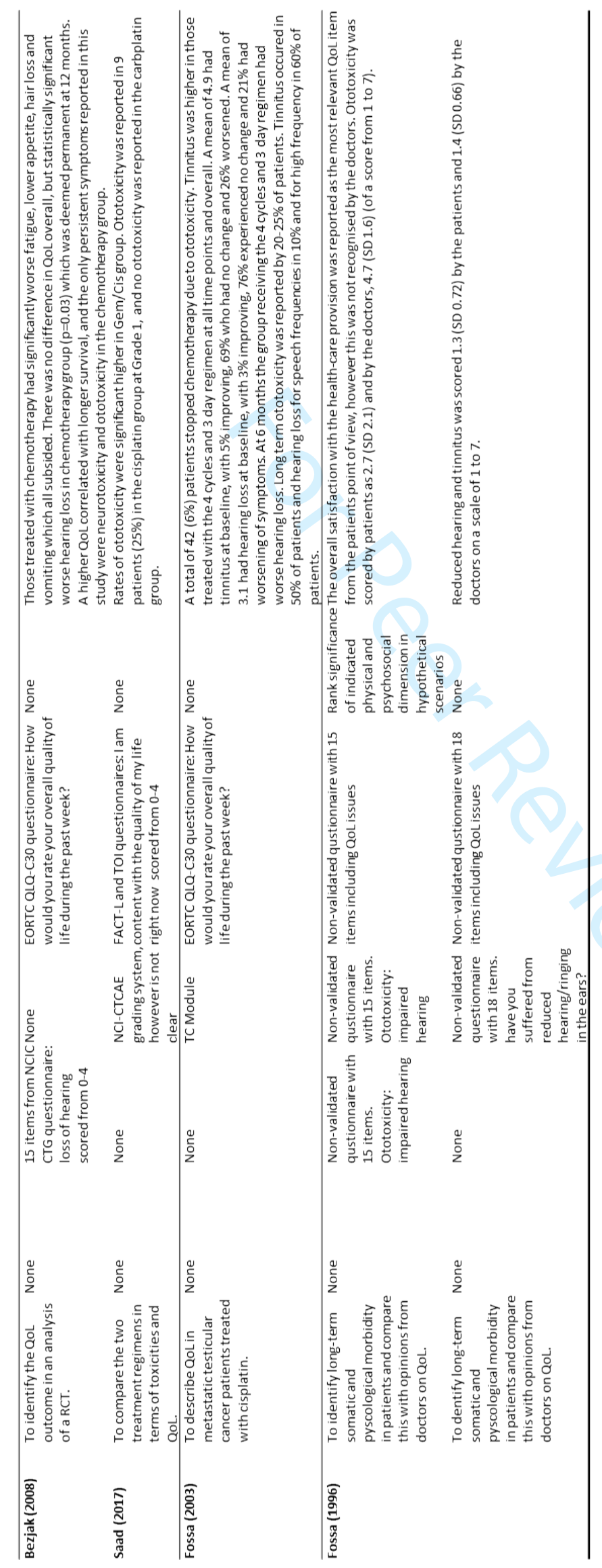

Table 3 continued. 


\section{Discussion}

Overall, the results found that those treated with platinum-based chemotherapy, specifically cisplatin, had significantly more hearing loss and tinnitus than the comparisonpopulation, with higher doses correlating to persisting symptoms. These results are corroborated by the wider literature, as it is reported that on average, $60-70 \%$ of adult patients experienced ototoxicity when treated with cisplatin (Chirtes and Albu 2016; Campbell and Le Prell 2018; Frisina et al. 2016; Travis et al. 2014). Tinnitus has also been reported in previous studies, particularly those with high doses of cisplatin (Campbell and Le Prell 2018). This review found that those with tinnitus and hearing loss were more likely to have a lower QoL.

It is common for there to be a reduction in QoL following the first three cycles of platinum-based chemotherapy in adults (Kalyanam et al. 2018). Furthermore, it is well documented that hearing loss negatively impacts mental wellbeing and QoL, although the use of hearing aids appear to improve general QoL within the first year, emphasising the importance of early and proper diagnosis (Hogan et al. 2015; Fellinger et al. 2007). Tinnitus has also been shown to be a significant burden on QoL and has a strong association with depression in the general population (Zeman et al. 2014; Nondahl et al. 2007). From this, it can be inferred that ototoxicity in cancer survivors can directly cause a reduction in QoL. However, due to the heterogeneity of the study designs and the lack of research carried out in this field, it cannot be categorically stated that this is true.

The studies included in this review were highly variable in both their methodology and results. The results clearly highlight the lack of standardisation in reporting QoL and ototoxicity diagnostics. Furthermore, the lack of grading means that individuals could be suffering from ototoxic effects and it not be reported adequately in study settings, or the opposite, where the reporting overestimates the ototoxic effect. Therefore, it is difficult to assess the strength of the results as a whole, as the nature of this field is heterogeneous. The 
lack of standardised diagnostic and grading systems is the most significant weakness in the reviewed studies. By pooling together similar data and carrying out a meta-analysis, powerful information could be identified and published, which in turn will help inform and develop better care and management for those experiencing ototoxicity. This research has typically consisted of a multitude of small-scale studies looking into different factors, making it difficult to compare information statistically. However, the information and data regarding genetic susceptibilities of ototoxicity have been statistically systematically analysed. Studies of high-quality and large population sizes have found that between $29-40 \%$ of testicular cancer patients have an ototoxic phenotype (Wheeler et al. 2015). Furthermore, a metaanalysis of phenotypes have found a multitude of genes, including those that play a role in calcium homeostasis and are associated with an increased risk of ototoxicity (Tserga et al. 2019).

Audiometry is a standardised and widely available method for quantifying hearing status. There are also a variety of validated tinnitus questionnaires that are used clinically for diagnosing and quantifying tinnitus severity readily available. Ideally, it should be clinical practise that in the event a patient presents with ototoxicity that these assessments be carried out. However, because chemotherapy is associated with many acute and life-threatening side effects, it is unrealistic and time-consuming to have measurement tools for each individual and specific side effect. However, it is of high clinical importance for the dose-limiting or permanent side effects to be identified and managed. For this reason, questionnaires such as the Scale for chemotherapy-induced long-term neurotoxicity (SCIN) which group together the neurotoxic side effects, are well-used outcome measures (Oldenburg et al. 2006). These type of assessments, although more time-efficient, lack collecting valid information. For example, the questions are vague and do not allow clinicians to differentiate one toxicity from another, meaning the management and support offered isn't useful. Another example of 
this is the Holistic Needs Assessment (HNA), which asks if "you have had any change in sight or hearing” (Wells, Semple, and Lane 2015; Biddle et al. 2016). This, although helpful in developing a tailored care plan, does not identify specific side effects, the severity of them or if it affects QoL. Furthermore, by identifying a change in hearing and/or sight, it is unclear which specialist the patients should be referred to, an optician or an audiologist? Therefore, the balance between not overwhelming a patient, yet also collecting reliable and detailed information about their side effects appears a seemingly impossible challenge. This has been highlighted regularly in literature, with many new proposals on which diagnostic criteria should be used to identify the presence and severity of ototoxicity, yet no standardised measures are implemented clinically at the present time (Theunissen et al. 2014; Chang 2011; Waissbluth, Peleva, and Daniel 2017; Crundwell, Gomersall, and Baguley 2016; Degeest et al. 2016).

There are many potential confounding factors when assessing ototoxicity and how it impacts quality of life, including age at treatment, number of follow-ups and the timing of these follow-ups, type of treatment, dosage of treatment, type of quality of life assessment and the setting these were carried out in. Furthermore, the language used in the assessment tools can also lead to patients providing unreliable and confusing information, which does not always reflect their true experience. The readability of the questionnaires, therefore, is also an important confounding factor that should be considered when analysing this type of information (Atcherson et al. 2013; Gray, Zraick, and Atcherson 2019; Douglas and KellyCampbell 2018).

The term "ototoxicity" must be defined when publishing trials and research studies. There needs to be a clear definition of what the authors mean, and differentiation between hearing loss and tinnitus information (Waissbluth, Peleva, and Daniel 2017). Without this, a detailed analysis on the severity and effect on QoL remains a challenge. 
Finally, although survival rates remain the priority in cancer treatment, there needs to be more emphasis on the importance of permanent toxicities. As people survive longer and it becomes clear that there will be a life beyond cancer, QoL becomes increasingly important. More awareness of how long-term toxicities, such as hearing loss and tinnitus, can affect QoL, needs to be integrated into clinical practice. By raising awareness, the risk of these issues being neglected will decrease. Patients guided through the survivorship journey can be given relevant and tailored support, be it hearing aids, tinnitus sound therapy or cognitive behavioural therapy (CBT). Ototoxicity is currently neither preventable nor curable, therefore it is essential that a deeper understanding and increased awareness of how hearing loss and tinnitus affects the QoL of cancer survivors be established in order to improve long-term symptom management.

\section{Acknowledgements}

This report is independent research by the National Institute for Health Research Biomedical Research Centre Funding Scheme. The views expressed in this publication are those of the author(s) and not necessarily those of the NHS, the National Institute for Health Research or the Department of Health.

\section{Declaration of Interest Statement}

None declared.

\section{References}

Alfano, Catherine M, and Julia Rowland. 2006. "Recovery Issues in Cancer Survivorship: A New Challenge for Supportive Care." The Cancer Journal 12 (5): 432-443. https://journals.lww.com/journalppo/Abstract/2006/09000/Recovery_Issues_in_Cancer_ Survivorship_A_New.12.aspx.

Atcherson, Samuel R., Cynthia M. Richburg, Richard I. Zraick, and Cassandra M. George. 2013. "Readability of Questionnaires Assessing Listening Difficulties Associated With (Central) Auditory Processing Disorders." Language, Speech, and Hearing Services in Schools 44 (1): 48-60. doi:10.1044/0161-1461(2012/11-0055).

Bentzen, Anne Gry, Lise Balteskard, Eva Hoff Wanderås, Gunilla Frykholm, Tom Wilsgaard, Olav Dahl, Marianne Grønlie Guren, et al. 2013. "Impaired Health-Related 
Quality of Life after Chemoradiotherapy for Anal Cancer : Late Effects in a National Cohort of 128 Survivors Impaired Health-Related Quality of Life after Chemoradiotherapy for Anal Cancer : Late Effects in a National Cohort of 128." doi:10.3109/0284186X.2013.770599.

Bezjak, Andrea, Christopher W Lee, Keyue Ding, Michael Brundage, Timothy Winton, Barbara Graham, Marlo Whitehead, et al. 2008. "Quality of Life Outcomes for Adjuvant Chemotherapy in Early-Stage Non - Small-Cell Lung Cancer : Results From a Randomized Trial, JBR.10." Journal of Clinical Oncology 26 (31). doi:10.1200/JCO.2007.12.6094.

Biddle, Lucy, Sangeetha Paramasivan, Susan Harris, Rona Campbell, James Brennan, and William Hollingworth. 2016. 'Patients' and Clinicians' Experiences of Holistic Needs Assessment Using a Cancer Distress Thermometer and Problem List: A Qualitative Study." European Journal of Oncology Nursing 23 (August). Churchill Livingstone: 59-65. doi:10.1016/J.EJON.2016.04.004.

Bisht, Manisha, and S. S. Bist. 2011. "Ototoxicity: The Hidden Menace.” Indian Journal of Otolaryngology and Head \& Neck Surgery 63 (3). Springer-Verlag: 255-259. doi:10.1007/s12070-011-0151-8.

Bokemeyer, C, C C Berger, J T Hartmann, C Kollmannsberger, H J Schmoll, M A Kuczyk, and L Kanz. 1998. "Analysis of Risk Factors for Cisplatin-Induced Ototoxicity in Patients with Testicular Cancer." British Journal of Cancer 77 (8). Nature Publishing Group: 1355-1362. http://www.ncbi.nlm.nih.gov/pubmed/9579846.

Bokemeyer, C, C C Berger, M A Kuczyk, and H J Schmoll. 1996. "Evaluation of Long-Term Toxicity after Chemotherapy for Testicular Cancer." Journal of Clinical Oncology 14 (11): 2923-2932. doi:10.1200/JCO.1996.14.11.2923.

Calhoun, Elizabeth A, D Ph, Charles L Bennett, D Ph, Patti A Peeples, D Ph, John R Lurain, Philip Y Roland, Jill M Weinstein, and David A Fishman. 1998. "Perceptions of Cisplatin-Related Toxicity among Ovarian Cancer Patients and Gynecologic Oncologists" 375: 369-375.

Campbell, Kathleen C. M., and Colleen G. Le Prell. 2018. "Drug-Induced Ototoxicity: Diagnosis and Monitoring." Drug Safety 41 (5): 451-464. doi:10.1007/s40264-0170629-8.

Chang, Kay W. 2011. "Clinically Accurate Assessment and Grading of Ototoxicity." Laryngoscope 121 (12): 2649-2657. doi:10.1002/lary.22376.

Chirtes, Felician, and Silviu Albu. 2016. "Prevention and Restoration of Hearing Loss Associated with the Use of Cisplatin.” BioMed Research International 2014 (July 2014). doi:10.1155/2014/925485.

Crundwell, Gemma, Phil Gomersall, and David M. Baguley. 2016. "Ototoxicity (Cochleotoxicity) Classifications: A Review." International Journal of Audiology 55 (2): 65-74. doi:10.3109/14992027.2015.1094188.

Deal, Jennifer A., Josh Betz, Kristine Yaffe, Tamara Harris, Elizabeth Purchase-Helzner, Suzanne Satterfield, Sheila Pratt, et al. 2016. "Hearing Impairment and Incident Dementia and Cognitive Decline in Older Adults: The Health ABC Study." The Journals of Gerontology Series A: Biological Sciences and Medical Sciences 72 (5): glw069. doi:10.1093/gerona/glw069. 
Degeest, S, P Corthals, I Dhooge, and H Keppler. 2016. "The Impact of Tinnitus Characteristics and Associated Variables on Tinnitus-Related Handicap." The Journal of Laryngology \& Otology 130 (01). Cambridge University Press: 25-31. doi:10.1017/S0022215115002716.

Douglas, Alana, and Rebecca J. Kelly-Campbell. 2018. "Readability of Patient-Reported Outcome Measures in Adult Audiologic Rehabilitation." American Journal of Audiology 27 (2): 208-218. doi:10.1044/2018_AJA-17-0095.

Fellinger, J., D. Holzinger, J. Gerich, and D. Goldberg. 2007. "Mental Distress and Quality of Life in the Hard of Hearing." Acta Psychiatrica Scandinavica 115 (3): 243-245. doi:10.1111/j.1600-0447.2006.00976.x.

Fosså, By Sophie D, Ronald De Wit, J Trevor Roberts, Peter M Wilkinson, Pieter H M De Mulder, Graham M Mead, Pat Cook, et al. 2003. "Quality of Life in Good Prognosis Patients With Metastatic Germ Cell Cancer : A Prospective Study of the European Organization for Research and Treatment of Cancer Cancer Study Group ( 30941 / TE20 )" 21 (6): 1107-1118. doi:10.1200/JCO.2003.02.075.

Fossa, Sophie D, and S D Fossg. 1996. "Patients' and Doctors ' Perception of Long-Term Morbidity in Patients with Testicular Cancer Clinical Stage I A Descriptive Pilot Study." Supportive Care in Cancer 4 (2): 118-128.

Frisina, Robert D, Heather E Wheeler, Sophie D Fossa, Sarah L Kerns, Chunkit Fung, Howard D Sesso, Patrick O Monahan, et al. 2016. "Comprehensive Audiometric Analysis of Hearing Impairment and Tinnitus After Cisplatin-Based Chemotherapy in Survivors of Adult-Onset Cancer." Journal of Clinical Oncology : Official Journal of the American Society of Clinical Oncology 34 (23). American Society of Clinical Oncology: 2712-2720. doi:10.1200/JCO.2016.66.8822.

Golder, Su, and Yoon Loke. 2009. "Search Strategies to Identify Information on Adverse Effects: A Systematic Review." Journal of the Medical Library Association : JMLA 97 (2): 84-92. doi:10.3163/1536-5050.97.2.004.

Gray, Sara A., Richard I. Zraick, and Samuel R. Atcherson. 2019. "Readability of Individuals With Disabilities Education Act Part B Procedural Safeguards: An Update." Language, Speech, and Hearing Services in Schools, April, 1-12. doi:10.1044/2018_LSHSS-180057.

Gurgel, Richard Klaus, Preston Daniel Ward, Sarah Schwartz, Maria C Norton, Norman L Foster, and JoAnn T Tschanz. 2014. "Relationship of Hearing Loss and Dementia: A Prospective, Population-Based Study." Otology \& Neurotology : Official Publication of the American Otological Society, American Neurotology Society [and] European Academy of Otology and Neurotology 35 (5). NIH Public Access: 775-781. doi:10.1097/MAO.0000000000000313.

Hogan, Anthony, Rebecca L. Phillips, Susan A. Brumby, Warwick Williams, and Catherine Mercer-Grant. 2015. "Higher Social Distress and Lower Psycho-Social Wellbeing: Examining the Coping Capacity and Health of People with Hearing Impairment." Disability and Rehabilitation 37 (22): 2070-2075. doi:10.3109/09638288.2014.996675.

Kalyanam, Balamurali, N Sarala, S M Azeem Mohiyuddin, and Ravi Diwakar. 2018. "Auditory Function and Quality of Life in Patients Receiving Cisplatin Chemotherapy in Head and Neck Cancer: A Case Series Follow-up Study.” Journal of Cancer Research 
and Therapeutics 14 (5). Medknow Publications and Media Pvt. Ltd.: 1099-1104. doi:10.4103/0973-1482.188426.

Kelland, Lloyd. 2007. "The Resurgence of Platinum-Based Cancer Chemotherapy." Nature Reviews Cancer 7 (8): 573-584. doi:10.1038/nrc2167.

Loke, Yoon K, Deirdre Price, and Andrew Herxheimer. 2007. "Systematic Reviews of Adverse Effects: Framework for a Structured Approach." BMC Medical Research Methodology 7 (1): 32. doi:10.1186/1471-2288-7-32.

Miaskowski, Christine, Judy Mastick, Steven M. Paul, Gary Abrams, Steven Cheung, Jennifer Henderson Sabes, Kord M. Kober, et al. 2018a. "Impact of ChemotherapyInduced Neurotoxicities on Adult Cancer Survivors' Symptom Burden and Quality of Life." Journal of Cancer Survivorship, November. Journal of Cancer Survivorship, 234245. doi:10.1007/s11764-017-0662-8.

Miaskowski, Christine, Judy Mastick, Steven M Paul, Gary Abrams, Steven Cheung, Jennifer Henderson Sabes, Kord M Kober, et al. 2018b. "Impact of Chemotherapy-Induced Neurotoxicities on Adult Cancer Survivors ' Symptom Burden and Quality of Life." Journal of Cancer Survivorship, 234-245.

Miaskowski, Christine, Steven M. Paul, Judy Mastick, Mark Schumacher, Yvette P. Conley, Betty Smoot, Gary Abrams, et al. 2018. "Hearing Loss and Tinnitus in Survivors with Chemotherapy-Induced Neuropathy.” European Journal of Oncology Nursing 32 (July 2017). Elsevier: 1-11. doi:10.1016/j.ejon.2017.10.006.

Miaskowski, Christine, Steven M Paul, Judy Mastick, Gary Abrams, Kimberly Topp, Betty Smoot, Kord M Kober, et al. 2018. "Associations Between Perceived Stress and Chemotherapy-Induced Peripheral Neuropathy and Otoxicity in Adult Cancer Survivors." Journal of Pain and Symptom Management. Elsevier Inc. doi:10.1016/j.jpainsymman.2018.02.021.

Mols, Floortje, Ad J.J.M. Vingerhoets, Jan Willem Coebergh, and Lonneke V. van de PollFranse. 2005. "Quality of Life among Long-Term Breast Cancer Survivors: A Systematic Review." European Journal of Cancer 41 (17). Pergamon: 2613-2619. doi:10.1016/J.EJCA.2005.05.017.

Nondahl, David M., Karen J. Cruickshanks, Dayna S. Dalton, Barbara E.K. Klein, Ronald Klein, Carla R. Schubert, Ted S. Tweed, and Terry L. Wiley. 2007. "The Impact of Tinnitus on Quality of Life in Older Adults." Journal of the American Academy of Audiology 18 (3): 257-266. doi:10.3766/jaaa.18.3.7.

Nordvik, Øyvind, Peder O. Laugen Heggdal, Jonas Brännström, Flemming Vassbotn, Anne Kari Aarstad, and Hans Jørgen Aarstad. 2018. "Generic Quality of Life in Persons with Hearing Loss: A Systematic Literature Review." BMC Ear, Nose and Throat Disorders 18 (1). BioMed Central: 1. doi:10.1186/s12901-018-0051-6.

Oldenburg, Jan, Sophie D Fossa, Alv A. Dahl, Sophie D. Fosså, and Alv A. Dahl. 2006. "Scale for Chemotherapy-Induced Long-Term Neurotoxicity (SCIN): Psychometrics, Validation, and Findings in a Large Sample of Testicular Cancer Survivors." Quality of Life Research 15 (5): 791-800. doi:10.1007/s11136-005-5370-6.

Oun, Rabbab, Yvonne E. Moussa, and Nial J. Wheate. 2018. "The Side Effects of PlatinumBased Chemotherapy Drugs: A Review for Chemists.” Dalton Transactions 47 (19). The Royal Society of Chemistry: 6645-6653. doi:10.1039/C8DT00838H. 
Paken, Jessica, Cyril D. Govender, Mershen Pillay, and Vikash Sewram. 2016. "CisplatinAssociated Ototoxicity: A Review for the Health Professional." Journal of Toxicology 2016. doi:10.1155/2016/1809394.

Saad, Amr Shafik, Ramy R Ghali, and May Ahmed Shawki. 2017. "A Prospective Randomized Controlled Study of Cisplatin versus Carboplatin-Based Regimen in Advanced Squamous Nonsmall Cell Lung Cancer." Journal of Cancer Research and Therapeutics 13 (2). Medknow Publications and Media Pvt. Ltd.: 198-203. doi:10.4103/0973-1482.187287.

Saladin, Shawn P, Robert B Perez, Bianca Cruz PharmD, Yasar Tasnif PharmD, CPM B Robert Perez Bianca Cruz, and PharmD Yasar Tasnif. 2015. "A Review of Ototoxic Medications: Implications for Professionals Working with Consumers with Hearing Loss." Journal of the American Deafness and Rehabilitation Association 49. http://repository.wcsu.edu/jadara.

Siegel, Rebecca L., Kimberly D. Miller, and Ahmedin Jemal. 2018. "Cancer Statistics, 2018." CA: A Cancer Journal for Clinicians 68 (1): 7-30. doi:10.3322/caac. 21442.

Skalleberg, Jakob, Olesya Solheim, Sophie D. Fosså, Milada Cvancarova Småstuen, Terje Osnes, Per Ole M. Gundersen, and Marie Bunne. 2017. "Long-Term Ototoxicity in Women after Cisplatin Treatment for Ovarian Germ Cell Cancer." Gynecologic Oncology 145 (1). Elsevier Inc.: 148-153. doi:10.1016/j.ygyno.2017.02.006.

Stein, Kevin D., Karen L. Syrjala, and Michael A. Andrykowski. 2008. "Physical and Psychological Long-Term and Late Effects of Cancer." Cancer 112 (S11). WileyBlackwell: 2577-2592. doi:10.1002/cncr.23448.

"Study Quality Assessment Tools | National Heart, Lung, and Blood Institute (NHLBI)." 2018. Accessed November 1. https://www.nhlbi.nih.gov/health-topics/study-qualityassessment-tools.

Theile, Dirk, and Dirk. 2017. "Under-Reported Aspects of Platinum Drug Pharmacology." Molecules 22 (3). Multidisciplinary Digital Publishing Institute: 382. doi:10.3390/molecules22030382.

Theunissen, Eleonoor A R, Wouter A. Dreschler, Merel N. Latenstein, Coen R N Rasch, Sieberen Van Der Baan, Jan Paul De Boer, Alfons J M Balm, and Charlotte L. Zuur. 2014. "A New Grading System for Ototoxicity in Adults." Annals of Otology, Rhinology and Laryngology 123 (10): 711-718. doi:10.1177/0003489414534010.

Travis, Lois B., Sophie D. Fossa, Howard D. Sesso, Robert D. Frisina, David N. Herrmann, Clair J. Beard, Darren R. Feldman, et al. 2014. "Chemotherapy-Induced Peripheral Neurotoxicity and Ototoxicity: New Paradigms for Translational Genomics." Journal of the National Cancer Institute 106 (5). doi:10.1093/jnci/dju044.

Tserga, Evangelia, Tara Nandwani, Niklas K. Edvall, Jan Bulla, Poulam Patel, Barbara Canlon, Christopher R. Cederroth, and David M. Baguley. 2019. "The Genetic Vulnerability to Cisplatin Ototoxicity: A Systematic Review." Scientific Reports 9 (1). Nature Publishing Group: 3455. doi:10.1038/s41598-019-40138-z.

Waissbluth, Sofia, Emilia Peleva, and Sam J. Daniel. 2017. "Platinum-Induced Ototoxicity: A Review of Prevailing Ototoxicity Criteria." European Archives of Oto-RhinoLaryngology 274 (3). Springer Berlin Heidelberg: 1187-1196. doi:10.1007/s00405-0164117-z. 
Wells, M., C.J. Semple, and C. Lane. 2015. “A National Survey of Healthcare Professionals' Views on Models of Follow-up, Holistic Needs Assessment and Survivorship Care for Patients with Head and Neck Cancer." European Journal of Cancer Care 24 (6). John Wiley \& Sons, Ltd (10.1111): 873-883. doi:10.1111/ecc.12285.

Wheeler, Heather E., Lois B. Travis, Amy Budnick, Darren Richard Feldman, Lawrence H. Einhorn, Robert James Hamilton, David J. Vaughn, et al. 2015. "Comprehensive Characterization of Cisplatin-Related Hearing Loss in U.S. and Canadian Testicular Cancer Survivors (TCS)." Journal of Clinical Oncology 33 (15_suppl). American Society of Clinical Oncology : 9570-9570. doi:10.1200/jco.2015.33.15_suppl.9570.

Zeman, Florian, Michael Koller, Berthold Langguth, and Michael Landgrebe. 2014. "Which Tinnitus-Related Aspects Are Relevant for Quality of Life and Depression: Results from a Large International Multicentre Sample." Health and Quality of Life Outcomes 12 (1). BioMed Central: 7. doi:10.1186/1477-7525-12-7. 
Cancer survivors treated with platinum-based chemotherapy affected by ototoxicity and the impact on quality of life: a narrative systematic review.

Objective: To identify any change in quality of life (QoL) An understanding of the impact on quality of life ( $\mathrm{Q} \odot \mathrm{L})$ caused by chemotherapy-induced toxicities, such as hearing loss and tinnitus, to provide is important to know ininformation in order to improve services and aid clinicians in their decision-making.

Design: This systematic review followed the PRISMA checklist. The search terms were cancer, platinum-based chemotherapy, ototoxicity and "quality of life" $Q_{0} L_{.-}$Titles and abstracts, followed by full texts, were screened by two independent researchers. The relevant data were extracted and quality analysis was performed using the NIH Quality Assessment Tool.

Study Sample: 308 titles and abstracts were screened, and 27 full text articles were screened. Ten articles representing 11 studies were included in the review. Study design included cross--sectional studies, randomised control trials and longitudinal studies.

Results: Diagnostic criteria consisted of audiograms, questionnaires, and patient complaints. The study quality ranged from $21.43 \%$ to $85.71 \%$. Overall results found that those treated with cisplatin had more hearing loss and tinnitus than those treated with other therapies. Furthermore, those with hearing loss and tinnitus were more likely to have a lower QoL.

Conclusions: There is an urgent need to standardise diagnostics when investigating ototoxicity and its effect on QoL, particularly for research into risk factors, prevention and management.

Keywords: cancer, platinum--based chemotherapy, survivorship, ototoxicity, hearing, tinnitus, quality of life 


\section{Introduction}

Cancer continues to be a life-altering diagnosis, however due to medical advances there has been an overall decline of $26 \%$ in cancer deaths within the past two decades (Siegel, Miller, and Jemal 2018). Treatment effects, howererthough, can often cause long-term physical and psychological challenges for survivors (Skalleberg et al. 2017; Alfano and Rowland 2006). For this reason, there is a requirementa need to look into how these long-term effects impact quality of life $(\mathrm{QoL})$ for those who are adapting to a life with and beyond cancer.

Platinum-based chemotherapy is typically used to treat most solid tumours, including breast, testicular and ovarian cancers (Oun, Moussa, and Wheate 2018; Theile and Dirk 2017; Kelland 2007). Due to its cost effective systematic and cytotoxic effects, it has been one of the most efficient and widely available chemotherapies (Paken et al. 2016). However, fit is widely known that platinum-based chemotherapy, although commonly used due to its eytotoxic effectiveness, can cause ototoxicity (Campbell and Le Prell 2018; Saladin et al. 2015). Ototoxicity refers to any hearing deficit or tinnitus resulting from a temporary or permanent inner ear dysfunction, following treatment with an ototoxic drug (Paken et al. 2016). Ototoxic drugs include aminoglycoside antibiotics such as gentamicin, loop diuretics such as torasemide and neurologic drugs, such as sodium valproate (Bisht and Bist 2011). Ototoxic effects commonly manifest as tinnitus and/or high frequency hearing loss-and tinnitus thatwhich can later progress to lower frequencies (Waissbluth, Peleva, and Daniel 2017). Both tinnitus and hearing loss These are associated with a higher risk of depression, social isolation, anxiety (Nordvik et al. 2018) and dementia (Gurgel et al. 2014; Deal et al. 2016)(Gurgel et al. 2014).

It may not be possible to identify the specific time point during treatment at which an effect first appears, making it challenging to determine the causality and risk of each therapy 
received (Stein, Syrjala, and Andrykowski 2008). For this reason, literature reporting adverse health effects associated with chemotherapy can be imprecise and lacking in detail.

Furthermore, collating systematic evidence on adverse effects can be difficult. Specific toxicities are rarely included in key words, titles or abstracts. To overcome this challenge, a compromise between sensitivity and precision must be made when performing a systematic search (Golder and Loke 2009).

To date, there have been no systematic reviews carried out exploring the impact on QoL from platinum-based chemotherapy_-induced ototoxicity.

\section{Materials and Methods \\ Eligibility Criteria}

The four themes which that had to be present in an article were: any mention of cancer, platinum-based chemotherapy, ototoxicity and quality of lifeQoL. Known key articles were checked in the searches to ensure all relevant articles were included in the search. There was no limitation on the date range of this search.

The inclusion criteria consisted of: any combination of treatments which included platinum-based chemotherapy for curative intent, any type of formal QoLquality of life assessment, any type of formal hearing loss and/or tinnitus assessment, written in the English language, any study design providing the relevant results were obtained after treatment and any cancer type other than head and neck. Any paediatric study was excluded, in addition to review articles, grey literature and both in vitro and in vivo studies.

\section{Information Sources}

This systematic review was conducted following the Preferred Reporting Items for Systematic Reviews and Meta-Analysis (PRISMA) checklist.

Due to the nature of this systematic review and the difficulties in searching for 
adverse effects of chemotherapy, specificity and precision were optimised in order to capture the most relevant articles and reduce unrelated articles. The terms used were edited accordingly to meet the standards of each search engine.

Search engines used were OVIDSP, NCBI, WebofScience and Cochrane. Databases searched therefore consisted of Medline, Pyschinfo and PyschArticles, Embase, PubMed, WebofScience Core Collection and the Cochrane Database.

\section{Study Selection}

Titles and abstracts were imported to Endnote, duplicates were removed and the remainder were screened by two independent authors (SP and JT) against the eligibility criteria. Any disagreement was resolved by consensus. Full-text articles of potentially relevant papers were also assessed for eligibility, ence again resolving any discrepancies by consensus.

\section{Data Extraction Process}

Determinants such as paper characteristics, type of study design, sample size, patient demographics, and the measurements used and analysed, in addition to the results of the specific study, were all extracted. The information which that could be compared across studies was then analysed accordingly, with the remaining information displayed as a description in order to capture the full results.

\section{Risk of Bias in Individual Studies}

A quality assessment was carried out on each of the studies included in this review using a 14-item study quality assessment tool involving pre-defined principles, the NIH's Quality Assessment Tools (“Study Quality Assessment Tools | National Heart, Lung, and Blood Institute (NHLBI)" 2018). An item was scored 1 for matching the criteria, and scored a score of 0 if it was not clear or did not match the criteria. Aggregate percentages were used to classifyA percentage was made from the scores and classified inte poor--quality $(\leq 50 \%)$, and high--quality $(>50 \%)$ studies. This tool was chosen based on a systematic review carried out 
by Mols, et.al (Mols et al. 20105). The tool was chosen as it assessed relevant aspects for each study type involved in this review. The--high quality and low--quality studies were grouped, and their results were compared to evaluate consistencies and anomalies.

\section{Synthesis of Results}

Due to the heterogeneity of the results reported in this review, it was not possible to statistically combine the results. Therefore, a narrative analysis was carried out ${ }_{2}$ and these descriptive results of each study were compared with one another.

Outcome measures from the studies were-all extracted and compared, including the diagnostic criteria and grading systems used.

\section{Risk of Bias Across Studies}

The majority of the adverse effects within the studies were not clearly defined, therefore the risk of bias between studies was relatively high. Moreover, not all diagnostic criteria were specified, meaning some studies reported presence of ototoxicity but did not clarify its severity or symptom characteristics, i.e. whether it was hearing loss or tinnitus. The nonrandomised studies were also considered to carry a high risk of bias, as trials without blinding are prone to bias (Loke, Price, and Herxheimer 2007).

\section{Results}

\section{Study Selection}

A total of 645 articles were identified through the database searches performed. From this, 337 articles were excluded due to duplications, grey literature and there being no abstracts available. The resulting 308 titles and abstracts were screened. The screening procedure can be seen inis then left 308 titles and abstracts to sereen, shown-in Figure 1. 


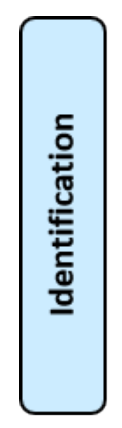

Records identified through database searching ( $n=645$ )

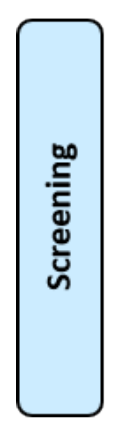

Titles and abstracts screened ( $n=308)$
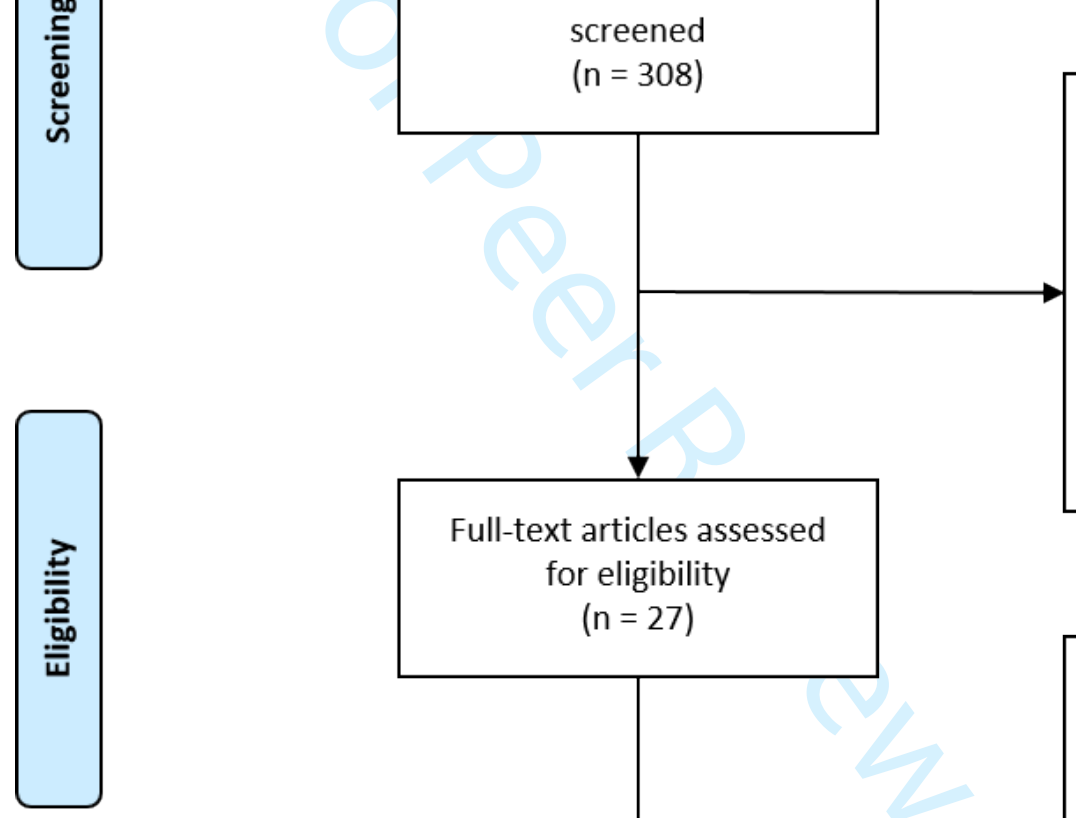

Records excluded $(n=281)$

Duplicates $(n=56)$

No full text $(n=3)$

In vivo studies $(\mathrm{n}=9)$

In vitro studies $(\mathrm{n}=10)$

Paediatric studies $(n=73)$

Grey literature $(n=8)$

Not relevant $(n=73)$

Review article $(n=49)$

$$
\begin{aligned}
& \text { Full-text articles assessed } \\
& \text { for eligibility } \\
& (n=27)
\end{aligned}
$$

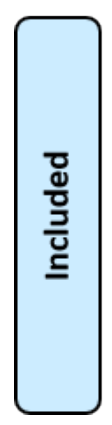

Full-text articles excluded ( $n=17)$

Not English language $(n=1)$

Not relevant to study $(n=6)$ Review ( $n=2)$

Paediatric studies $(n=1)$

Grey Literature $(n=6)$

Palliative care $(n=1)$

Studies included in qualitative synthesis $(n=10)$

Figure 1 displaying the PRISMA flowchart methodology and results obtained for this systematic review. 


\section{Study Characteristics}

The following study characteristics were extracted, as shown in Table 1: location of study, type of study design, population characteristics, number of participants, number of participants treated with platinum--based chemotherapy, diagnostic measurements for ototoxicity, hearing loss, tinnitus and QoLquality of life, type of platinum-based chemotherapy, follow-up period, if any, main objective of study and a descriptive summary of the study.

There were six 6 cross-sectional studies included in this systematic review, each with variable timeframes since diagnosis_(Bentzen et al. 2013; Bokemeyer et al. 1996; Calhoun et al. 1998; Miaskowski, Paul, Mastick, Schumacher, et al. 2018; Miaskowski, Paul, Mastick, Abrams, et al. 2018; Miaskowski, Mastick, Paul, Abrams, et al. 2018b). In total, 856 participants were included; 565 of these received platinum-based chemotherapy. Two randomised control trials compared cisplatin-based regimens with other types of treatments and included 553 patients, with 313 of these having a platinum-based treatment_(Bezjak et al. 2008; Saad, Ghali, and Shawki 2017). Only one longitudinal study was included in this systematic review, following 666 patients with metastatic testicular cancer on two different cisplatin regimens, with 286 (52\%) being followed up at 2 years_(Fosså et al. 2003). Finally, one paper involved two separate pilot studies on low-stage testicular cancer survivors from Norway and the UK_(Fossa and Fossg 1996). This study involved comparing opinions on toxicities of those treated with infradiaphragmatic radiotherapy, cisplatin, or surveillance and the opinions of a variety of healthcare professionals. From the 309 participants involved, 71 of these received cisplatin(Fossa and Fossg 1996).

Most did not report the demographics within each comparison group, but as a whole. For example, the Bentzen, et_al. paper describes patient characteristics as $79 \%$ women and $21 \%$ men, with a median age of 61 , and a range of $40-89$ years old for survivors who 
responded to the survey (Bentzen et al. 2013). Although the information contains those treated with cisplatin $(n=56)$, it is not possible to isolate the gender split and age range of this exact subgroup.

Eight of the studies included cisplatin as the platinum-based chemotherapy, and

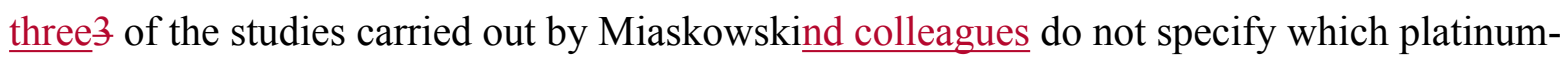
based chemotherapy was used (Miaskowski, Paul, Mastick, Abrams, et al. 2018; Miaskowski, Mastick, Paul, Abrams, et al. 2018a; Miaskowski, Paul, Mastick, Schumacher, et al. 2018). Only one study investigated the difference between carboplatin and cisplatin (Saad, Ghali, and Shawki 2017). Moreover, only one study compared the toxicities with those treated with cisplatin to the normal population (Bentzen et al. 2013). 


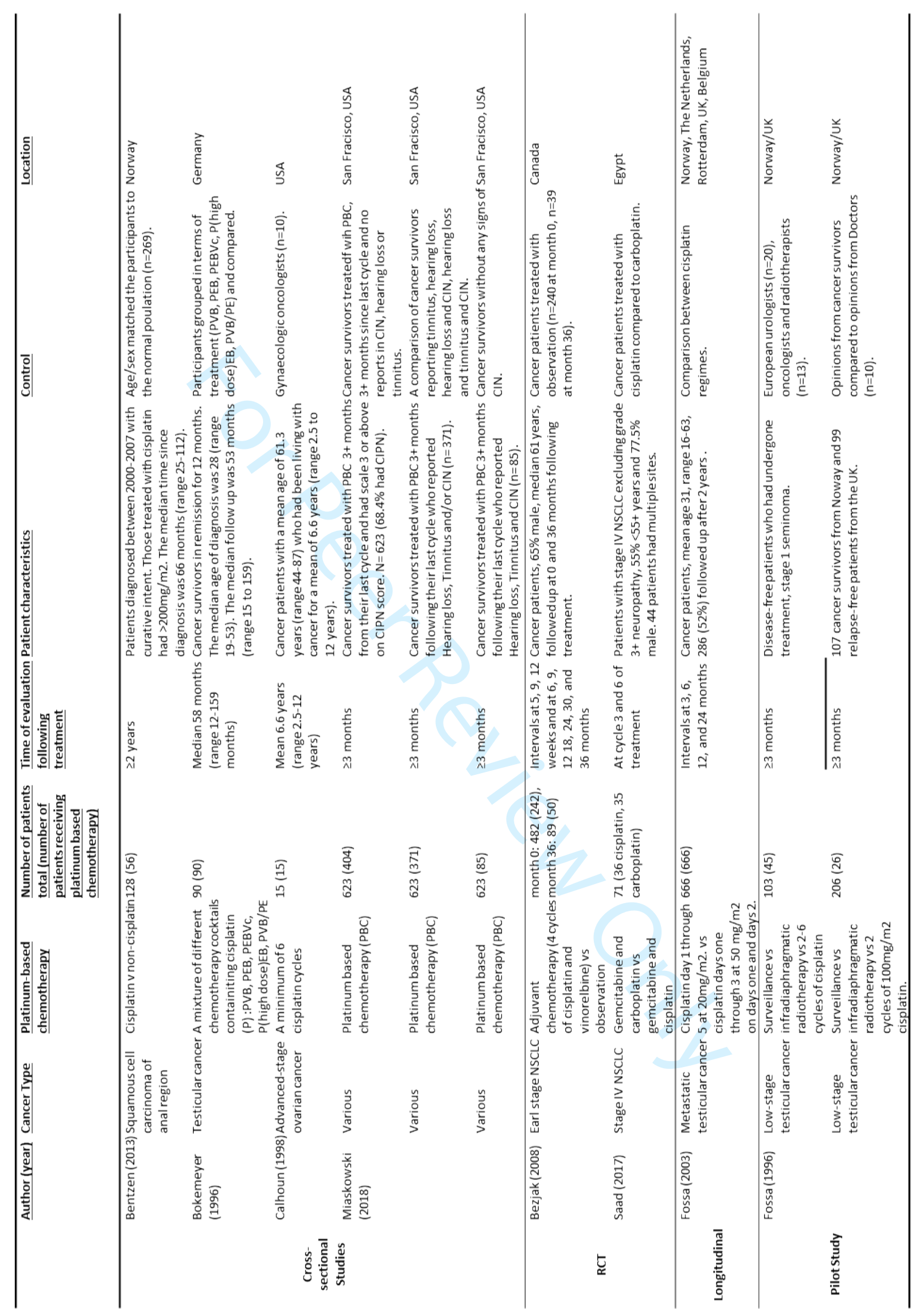

Table 1 displays the study characteristics extracted for this review, including the author, type of study, cancer type, type of platinum-based chemotherapy used, number of participants involved and number of participants involved treated with platinum-based chemotherapy 


\section{Risk of Bias}

The NIH Quality Assessment Tool (“Study Quality Assessment Tools | National Heart, Lung, and Blood Institute (NHLBI)" 2018)_were carried outwas used to assess - on-each of the individual studies. The appraisal criteria involved answering 14 binary questions on the quality of the article. Table 2 displays the quality score for each assessment and the quality percentage calculated, with green being a good--quality study and red being a poor--quality study. Those with a score of $>50 \%(\mathrm{n}=7)$ were classed as a highgøed--quality study, and those $\leq 50 \%(n=4)$ were classed as a poor-quality -study. The studies were grouped according to quality to compare any differences in results and identify any contradicting information.

The papers with a quality score $\leq 50 \%(n=4)$ all compared opinions of patients and healthcare professionals. The papers concluded that most patients perceived the effects of ototoxicity as tolerable, whereas those in health professions perceived the toxicity to affect QoL. However, these studies were all based on hypothetical scenarios and not real life experiences, therefore it could be hypothesised that patients may not realise the extent to which how QoLquality of life can change when experiencing ototoxicity, compared to professionals. All but one study scoring $>50 \%$ concluded that QoL is indeed affected by tinnitus and/or hearing loss, adding that severity correlated with the dosage and number of cycles. However, one high quality study carried out by Bezjack, et.al. 2008 found no difference in the QoL assessed across different treatments, regardless of experiencing ototoxicity. Yet, this study found that ototoxicity did indeed persist beyond treatment (Bezjak et al. 2008). There were no significant differences in results from the high quality studies compared to the lower quality studies. 


\begin{tabular}{|c|c|c|c|c|c|c|c|c|c|c|c|}
\hline \multirow{2}{*}{$\begin{array}{l}\text { Author (year) } \\
\text { Quality analysis }\end{array}$} & \multirow{2}{*}{$\begin{array}{l}\begin{array}{l}\text { Bentzen } \\
\text { (2013) }\end{array} \\
7 / 14\end{array}$} & \multicolumn{2}{|c|}{$\begin{array}{l}\text { Bokemeyer Calhoun } \\
\text { (1996) (1998) }\end{array}$} & \multicolumn{3}{|c|}{ Miaskowski (2018) } & \multirow{2}{*}{$\begin{array}{l}\begin{array}{l}\text { Bezjak } \\
(2008)\end{array} \\
11 / 14 \\
\end{array}$} & \multirow{2}{*}{$\begin{array}{l}\begin{array}{l}\text { Saad } \\
(2017)\end{array} \\
9 / 14\end{array}$} & \multirow{2}{*}{$\begin{array}{l}\begin{array}{l}\text { Fossa } \\
(2003)\end{array} \\
12 / 14 \\
\end{array}$} & \multicolumn{2}{|c|}{ Fossa (1996) } \\
\hline & & $9 / 14$ & $7 / 14$ & $10 / 14$ & $10 / 14$ & $9 / 14$ & & & & $3 / 14$ & $3 / 14$ \\
\hline & $50.00 \%$ & $64.29 \%$ & $50.00 \%$ & $71.43 \%$ & $71.43 \%$ & $64.29 \%$ & $78.57 \%$ & $64.29 \%$ & $85.71 \%$ & $21.43 \%$ & $21.43 \%$ \\
\hline
\end{tabular}

Table 2 displays the study and the critical appraisal score for each study, using the NIH Quality Assessment Tool. 


\section{Results of the Individual Studies}

0

11

12

13

14

15

16

17

18

19

20

21

22

23

24

25

26

27

28

29

30

31

32

33

34

35

36

37

38

39

40

41

42

43

44

45

46

47

48

49

50

51

52

53

54

55

56

57

58

59

60 


\section{The data extracted in}

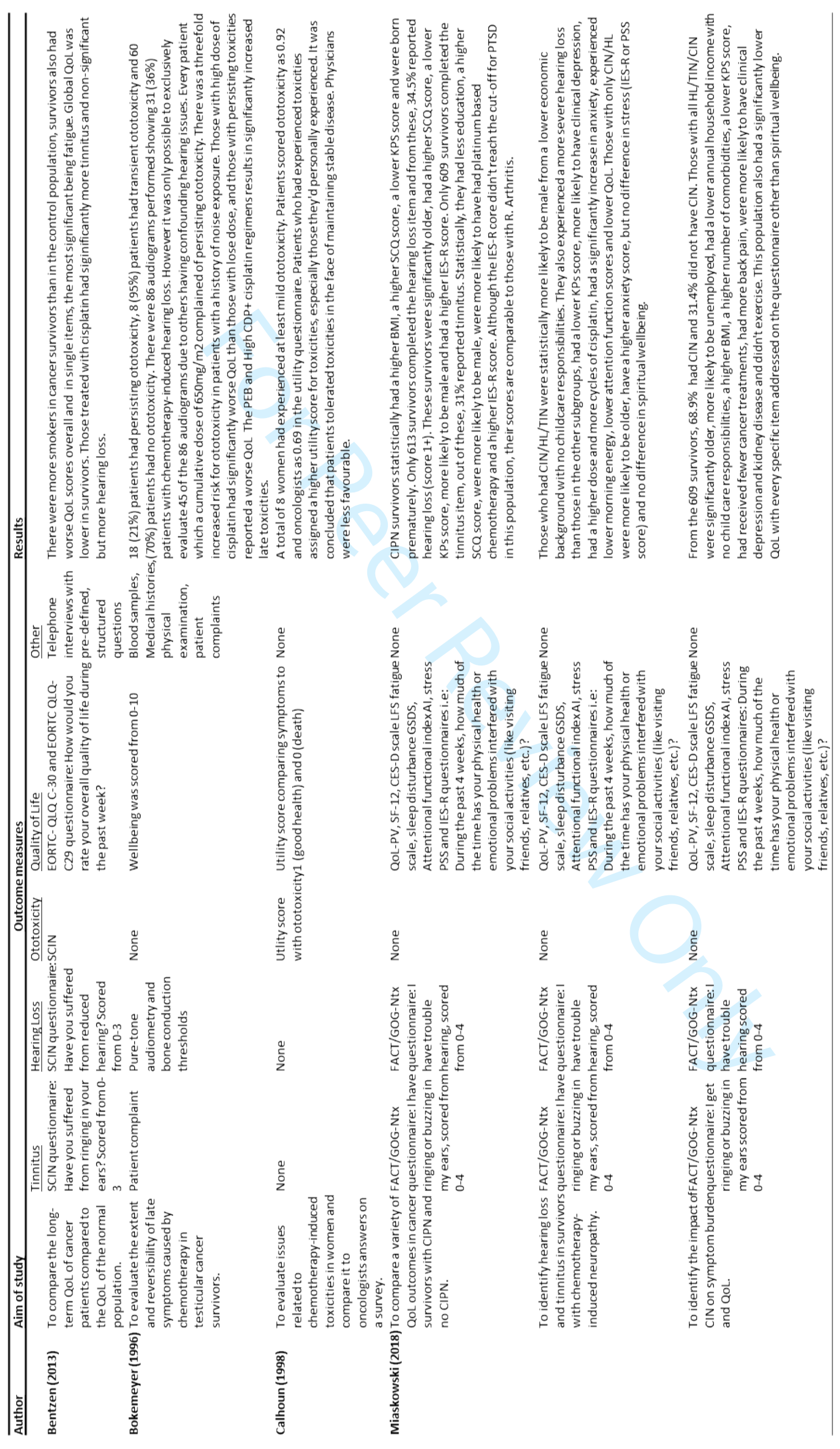


Table 3 demonstrates that there is no standardised outcome measurement used to assess ototoxicity. For example, many of the measurements used in the study analysed ototoxicity, yet did not specify or define ototoxicity. These studies could have measured either hearing loss or tinnitus. Furthermore, many studies did not consider the severity or grading of ototoxicity. One study did, however, perform pure tone audiometry with bone conduction thresholds on patients to assess the extent of their hearing loss (Bokemeyer et al. 1998). The studies carried out by Miaskowski assessed 8 aspects of QoL in addition to a questionnaire identifying the severity of hearing loss and the severity of tinnitus as separate items., which was definedTinnitus was defined as "ringing or buzzing in the ears" (Miaskowski, Paul, Mastick, Schumacher, et al. 2018; Miaskowski, Mastick, Paul, Abrams, et al. 2018a; Miaskowski, Paul, Mastick, Abrams, et al. 2018). The studies compared those with hearing loss, tinnitus and neuropathy to those with just one of the toxicities and those with no toxicities. However, these studies do not report which platinum-based chemotherapy iwass used, the regimen used, the dosage or how many cycles each patient received. 


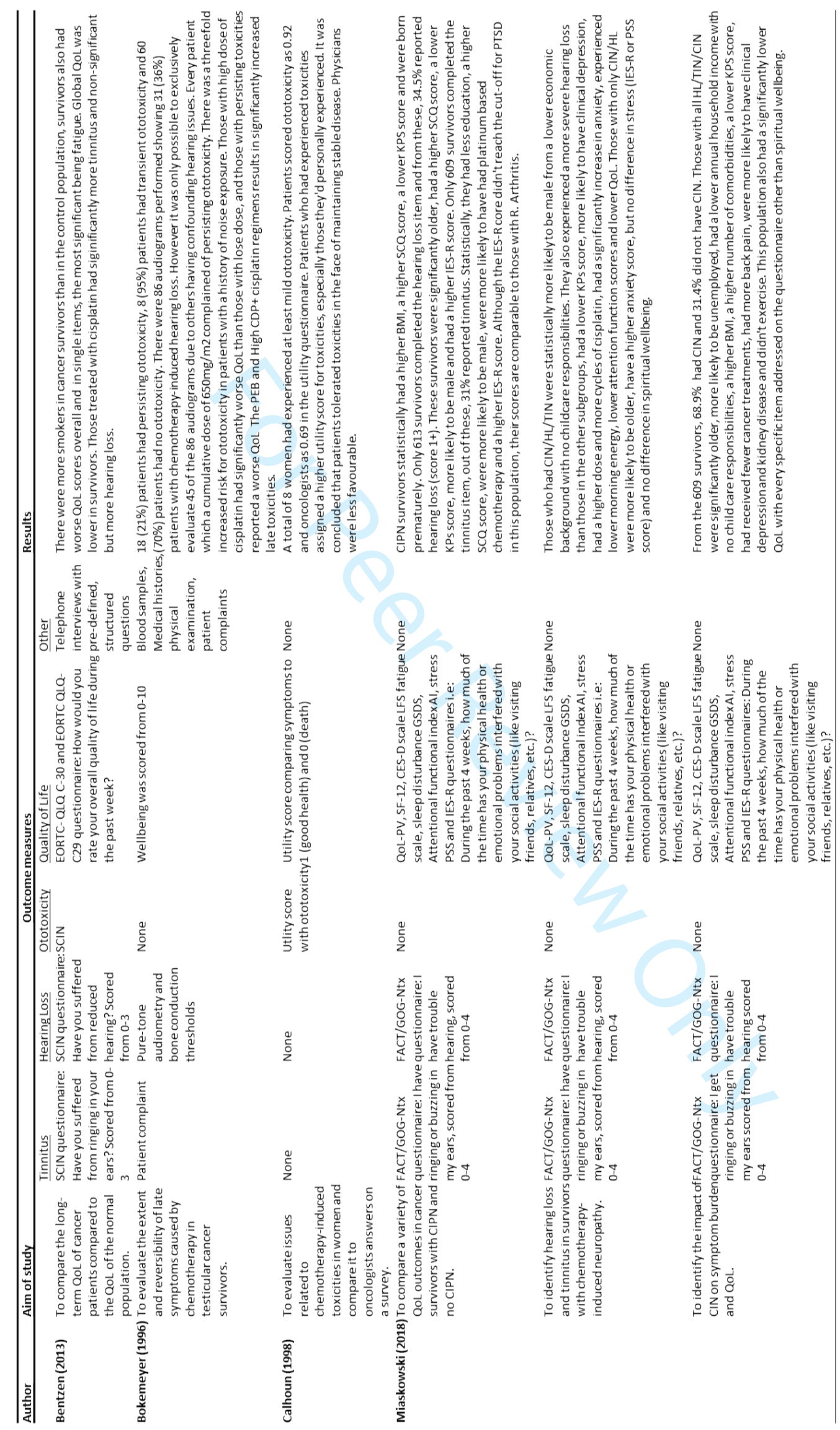

Table 3 displays the results extracted from the individual studies in the systematic review. 


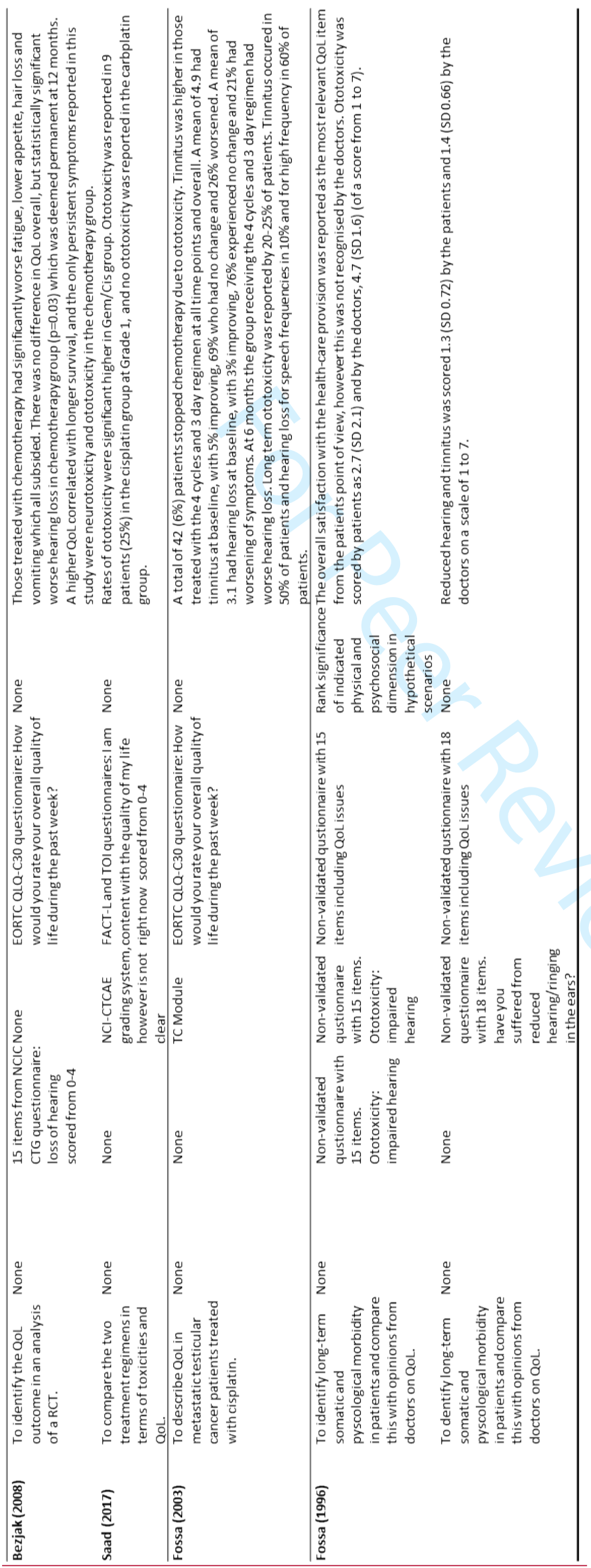

Table 3 continued. 


\section{Discussion}

Overall, the results found that those treated with platinum-_based chemotherapy, specifically cisplatin, had significantly more hearing loss and tinnitus than the comparisoned-population, with higher doses correlating to persisting symptoms. These results are corroborated by the wider This correlates with the wider literature, as it is reported thatn on average, $60-70 \%$ of adult patients experienced ototoxicity when treated with cisplatin (Chirtes and Albu 2016; Campbell and Le Prell 2018; Frisina et al. 2016; Travis et al. 2014)(Chirtes and Albu 2016; Campbell and Le Prell 2018). Tinnitus has also been reported in previous studies, particularly those with high doses of cisplatin (Campbell and Le Prell 2018). This review found that; those with tinnitus and hearing loss were more likely to have a lower QoL.

It is common for there to be a reduction in QoL following the first three cycles of platinum-based chemotherapy in adults (Kalyanam et al. 2018). Furthermore, it is well documented that hearing loss negatively impacts mental wellbeing and QoL, although the use of hearing aids appear to improve general QoL within the first year, emphasising the importance of early and proper diagnosisties (Hogan et al. 2015; Fellinger et al. 2007). Tinnitus has also been shown to be a significant burden on QoL and has a strong associationrelationship with depression in the general population (Zeman et al. 2014; Nondahl et al. 2007). From this, it can be inferred that indeed, ototoxicity in cancer survivors can directly cause a reduction in QoL. However, due to the heterogeneity of the study designs and the lack of research carried out in this field, it cannot be categorically stated that this is true.

The studies included in this review were highly variable in both their methodology and results. The results clearly highlight the lack of standardisation in reporting QoLquality 
ef life and ototoxicity diagnostics. Furthermore, the lack of grading means that individuals could be suffering from ototoxic effects and it not be reported adequately in study settings, or the opposite, where the reporting overestimates the ototoxic effect. Therefore, it is difficult to assess the strength of the results as a whole, as the nature of this field is heterogeneous. The lack of standardised diagnostic and grading systems is the most significant weakness in the reviewed studies. By pooling together similar data and carrying out a meta-analysis, powerful information could be identified and published, which in turn will help inform and develop better care and management for those experiencing ototoxicity. This research has typically consisted of a multitude of small-scale studies looking into different factors, making it difficult to compare information statistically. However, the information and data regarding genetic susceptibilities of ototoxicity have been statistically systematically analysed. Studies of high-quality and large population sizes have found that between $29-40 \%$ of testicular cancer patients have an ototoxic phenotype (Wheeler et al. 2015). Furthermore, a metaanalysis of phenotypes have found a multitude of genes, including those that play a role in calcium homeostasis and are associated with an increased risk of ototoxicity (Tserga et al. 2019).

Audiometry is a standardised and widely available method for quantifying hearing $\underline{\text { status. There are also a variety of validated tinnitus questionnaires that are used clinically for }}$ diagnosing and quantifying tinnitus severity readily available. Ideally, it should be clinical practise that in the event a patient presents with ototoxicity that these assessments be carried out. However, because chemotherapy is associated with many acute and life-threatening side effects, it is unrealistic and time-consuming to have measurement tools for each individual and specific side effect. However, it is of high clinical importance for the dose-limiting or permanent side effects to be identified and managed. For this reason, questionnaires such as $\underline{\text { the Scale for chemotherapy-induced long-term neurotoxicity (SCIN) which group together }}$ 
$\underline{\text { the neurotoxic side effects, are well-used outcome measures (Oldenburg et al. 2006). These }}$ type of assessments, although more time-efficient, lack collecting valid information. For example, the questions are vague and do not allow clinicians to differentiate one toxicity from another, meaning the management and support offered isn't useful. Another example of this is the Holistic Needs Assessment (HNA), which asks if "you have had any change in sight or hearing" (Wells, Semple, and Lane 2015; Biddle et al. 2016). This, although helpful in developing a tailored care plan, does not identify specific side effects, the severity of them or if it affects QoL. Furthermore, by identifying a change in hearing ande/or sight, it is unclear which specialist the patients should be referred to, an optician or an audiologist? Therefore, the is-balance between not overwhelming a patient, yet also collecting reliable and detailed information about their side effects appears a seemingly impossible challenge. This has been highlighted regularly in literature, with many new proposals on which diagnostic criteria should be used to identify the presence and severity of ototoxicity, yet no standardised measures are implemented clinically at the present time (Theunissen et al. 2014; Chang 2011; Waissbluth, Peleva, and Daniel 2017; Crundwell, Gomersall, and Baguley 2016; Degeest et al. 2016).

There are many potential confounding factors when assessing ototoxicity and how it impacts quality of life, including age at treatment, number of follow-ups and the timing of $\underline{\text { these follow-ups, type of treatment, dosage of treatment, type of quality of life assessment }}$ and the setting these were carried out in. Furthermore, the language used in the assessment tools can also lead to patients providing unreliable and confusing information, which does not always reflect their true experience. The readability of the questionnaires, therefore, is also an important confounding factor that should be considered when analysing this type of information (Atcherson et al. 2013; Gray, Zraick, and Atcherson 2019; Douglas and KellyCampbell 2018). 
The term "ototoxicity" must be defined when publishing trials and research studies. There needs to be a clear definition of what the authors mean, and differentiation between hearing loss and tinnitus informationdifferentiate between hearing loss and tinnitus (Waissbluth, Peleva, and Daniel 2017). Without this, a detailed analysis on the severity and effect on QoL remains a challenge.

FinallyLastly, although survival rates remain the priority in cancer treatment, there needs to be more emphasis on the importance of permanent toxicities. As people survive longer and it becomes clear that there will be a life beyond cancer, QoL becomes increasingly important. More awareness of how long-term toxicities, such as hearing loss and tinnitus, can affect QoL, needs to be integrated into clinical practice. By raising awareness, the risk of these issues being neglected will decrease. Patients guided through the survivorship journey can be given relevant and tailored support, be it hearing aids, tinnitus sound therapy or cognitive behavioural therapy (CBT). Ototoxicity is currently neither preventable nor curable, therefore it is essential that a deeper understanding and increased awareness of how hearing loss and tinnitus affects the QoL of cancer survivors be established in order to improve longterm symptom management.

\section{Acknowledgements}

This report is independent research by the National Institute for Health Research Biomedical Research Centre Funding Scheme. The views expressed in this publication are those of the author(s) and not necessarily those of the NHS, the National Institute for Health Research or the Department of Health.

\section{Declaration of Interest Statement}

None declaredDecaled. 


\section{References}

Alfano, Catherine M, and Julia Rowland. 2006. "Recovery Issues in Cancer Survivorship: A New Challenge for Supportive Care." The Cancer Journal 12 (5): 432-443. https://journals.lww.com/journalppo/Abstract/2006/09000/Recovery_Issues_in_Cancer_ Survivorship_A_New.12.aspx.

Atcherson, Samuel R., Cynthia M. Richburg, Richard I. Zraick, and Cassandra M. George. 2013. "Readability of Questionnaires Assessing Listening Difficulties Associated With (Central) Auditory Processing Disorders." Language, Speech, and Hearing Services in Schools 44 (1): 48-60. doi:10.1044/0161-1461(2012/11-0055).

Bentzen, Anne Gry, Lise Balteskard, Eva Hoff Wanderås, Gunilla Frykholm, Tom Wilsgaard, Olav Dahl, Marianne Grønlie Guren, et al. 2013. "Impaired Health-Related Quality of Life after Chemoradiotherapy for Anal Cancer : Late Effects in a National Cohort of 128 Survivors Impaired Health-Related Quality of Life after Chemoradiotherapy for Anal Cancer : Late Effects in a National Cohort of 128." doi:10.3109/0284186X.2013.770599.

Bezjak, Andrea, Christopher W Lee, Keyue Ding, Michael Brundage, Timothy Winton, Barbara Graham, Marlo Whitehead, et al. 2008. "Quality of Life Outcomes for Adjuvant Chemotherapy in Early-Stage Non - Small-Cell Lung Cancer : Results From a Randomized Trial, JBR.10." Journal of Clinical Oncology 26 (31). doi:10.1200/JCO.2007.12.6094.

Biddle, Lucy, Sangeetha Paramasivan, Susan Harris, Rona Campbell, James Brennan, and William Hollingworth. 2016. 'Patients' and Clinicians' Experiences of Holistic Needs Assessment Using a Cancer Distress Thermometer and Problem List: A Qualitative Study." European Journal of Oncology Nursing 23 (August). Churchill Livingstone: 59-65. doi:10.1016/J.EJON.2016.04.004.

Bisht, Manisha, and S. S. Bist. 2011. “Ototoxicity: The Hidden Menace.” Indian Journal of Otolaryngology and Head \& Neck Surgery 63 (3). Springer-Verlag: 255-259. doi:10.1007/s12070-011-0151-8.

Bokemeyer, C, C C Berger, J T Hartmann, C Kollmannsberger, H J Schmoll, M A Kuczyk, and L Kanz. 1998. "Analysis of Risk Factors for Cisplatin-Induced Ototoxicity in Patients with Testicular Cancer.” British Journal of Cancer 77 (8). Nature Publishing Group: 1355-1362. http://www.ncbi.nlm.nih.gov/pubmed/9579846.

Bokemeyer, C, C C Berger, M A Kuczyk, and H J Schmoll. 1996. "Evaluation of Long-Term Toxicity after Chemotherapy for Testicular Cancer." Journal of Clinical Oncology 14 (11): 2923-2932. doi:10.1200/JCO.1996.14.11.2923.

Calhoun, Elizabeth A, D Ph, Charles L Bennett, D Ph, Patti A Peeples, D Ph, John R Lurain, Philip Y Roland, Jill M Weinstein, and David A Fishman. 1998. "Perceptions of Cisplatin-Related Toxicity among Ovarian Cancer Patients and Gynecologic Oncologists" 375: 369-375.

Campbell, Kathleen C. M., and Colleen G. Le Prell. 2018. "Drug-Induced Ototoxicity: Diagnosis and Monitoring." Drug Safety 41 (5): 451-464. doi:10.1007/s40264-0170629-8.

Chang, Kay W. 2011. "Clinically Accurate Assessment and Grading of Ototoxicity." Laryngoscope 121 (12): 2649-2657. doi:10.1002/lary.22376. 
Chirtes, Felician, and Silviu Albu. 2016. "Prevention and Restoration of Hearing Loss Associated with the Use of Cisplatin." BioMed Research International 2014 (July 2014). doi:10.1155/2014/925485.

Crundwell, Gemma, Phil Gomersall, and David M. Baguley. 2016. "Ototoxicity (Cochleotoxicity) Classifications: A Review." International Journal of Audiology 55 (2): 65-74. doi:10.3109/14992027.2015.1094188.

Deal, Jennifer A., Josh Betz, Kristine Yaffe, Tamara Harris, Elizabeth Purchase-Helzner, Suzanne Satterfield, Sheila Pratt, et al. 2016. "Hearing Impairment and Incident Dementia and Cognitive Decline in Older Adults: The Health ABC Study." The Journals of Gerontology Series A: Biological Sciences and Medical Sciences 72 (5): glw069. doi:10.1093/gerona/glw069.

Degeest, S, P Corthals, I Dhooge, and H Keppler. 2016. "The Impact of Tinnitus Characteristics and Associated Variables on Tinnitus-Related Handicap." The Journal of Laryngology \& Otology 130 (01). Cambridge University Press: 25-31. doi:10.1017/S0022215115002716.

Douglas, Alana, and Rebecca J. Kelly-Campbell. 2018. "Readability of Patient-Reported Outcome Measures in Adult Audiologic Rehabilitation." American Journal of Audiology 27 (2): 208-218. doi:10.1044/2018_AJA-17-0095.

Fellinger, J., D. Holzinger, J. Gerich, and D. Goldberg. 2007. "Mental Distress and Quality of Life in the Hard of Hearing." Acta Psychiatrica Scandinavica 115 (3): 243-245. doi:10.1111/j.1600-0447.2006.00976.x.

Fosså, By Sophie D, Ronald De Wit, J Trevor Roberts, Peter M Wilkinson, Pieter H M De Mulder, Graham M Mead, Pat Cook, et al. 2003. "Quality of Life in Good Prognosis Patients With Metastatic Germ Cell Cancer: A Prospective Study of the European Organization for Research and Treatment of Cancer Cancer Study Group ( 30941 / TE20 )" 21 (6): 1107-1118. doi:10.1200/JCO.2003.02.075.

Fossa, Sophie D, and S D Fossg. 1996. "Patients ' and Doctors 'Perception of Long-Term Morbidity in Patients with Testicular Cancer Clinical Stage I A Descriptive Pilot Study." Supportive Care in Cancer 4 (2): 118-128.

Frisina, Robert D, Heather E Wheeler, Sophie D Fossa, Sarah L Kerns, Chunkit Fung, Howard D Sesso, Patrick O Monahan, et al. 2016. "Comprehensive Audiometric Analysis of Hearing Impairment and Tinnitus After Cisplatin-Based Chemotherapy in Survivors of Adult-Onset Cancer." Journal of Clinical Oncology: Official Journal of the American Society of Clinical Oncology 34 (23). American Society of Clinical Oncology: 2712-2720. doi:10.1200/JCO.2016.66.8822.

Golder, Su, and Yoon Loke. 2009. "Search Strategies to Identify Information on Adverse Effects: A Systematic Review." Journal of the Medical Library Association : JMLA 97 (2): 84-92. doi:10.3163/1536-5050.97.2.004.

Gray, Sara A., Richard I. Zraick, and Samuel R. Atcherson. 2019. "Readability of Individuals With Disabilities Education Act Part B Procedural Safeguards: An Update." Language, Speech, and Hearing Services in Schools, April, 1-12. doi:10.1044/2018_LSHSS-180057.

Gurgel, Richard Klaus, Preston Daniel Ward, Sarah Schwartz, Maria C Norton, Norman L Foster, and JoAnn T Tschanz. 2014. "Relationship of Hearing Loss and Dementia: A 
Prospective, Population-Based Study." Otology \& Neurotology : Official Publication of the American Otological Society, American Neurotology Society [and] European Academy of Otology and Neurotology 35 (5). NIH Public Access: 775-781. doi:10.1097/MAO.0000000000000313.

Hogan, Anthony, Rebecca L. Phillips, Susan A. Brumby, Warwick Williams, and Catherine Mercer-Grant. 2015. "Higher Social Distress and Lower Psycho-Social Wellbeing: Examining the Coping Capacity and Health of People with Hearing Impairment." Disability and Rehabilitation 37 (22): 2070-2075. doi:10.3109/09638288.2014.996675.

Kalyanam, Balamurali, N Sarala, S M Azeem Mohiyuddin, and Ravi Diwakar. 2018. "Auditory Function and Quality of Life in Patients Receiving Cisplatin Chemotherapy in Head and Neck Cancer: A Case Series Follow-up Study." Journal of Cancer Research and Therapeutics 14 (5). Medknow Publications and Media Pvt. Ltd.: 1099-1104. doi:10.4103/0973-1482.188426.

Kelland, Lloyd. 2007. "The Resurgence of Platinum-Based Cancer Chemotherapy." Nature Reviews Cancer 7 (8): 573-584. doi:10.1038/nrc2167.

Loke, Yoon K, Deirdre Price, and Andrew Herxheimer. 2007. "Systematic Reviews of Adverse Effects: Framework for a Structured Approach.” BMC Medical Research Methodology 7 (1): 32. doi:10.1186/1471-2288-7-32.

Miaskowski, Christine, Judy Mastick, Steven M. Paul, Gary Abrams, Steven Cheung, Jennifer Henderson Sabes, Kord M. Kober, et al. 2018a. "Impact of ChemotherapyInduced Neurotoxicities on Adult Cancer Survivors' Symptom Burden and Quality of Life." Journal of Cancer Survivorship, November. Journal of Cancer Survivorship, 234245. doi:10.1007/s11764-017-0662-8.

Miaskowski, Christine, Judy Mastick, Steven M Paul, Gary Abrams, Steven Cheung, Jennifer Henderson Sabes, Kord M Kober, et al. 2018b. "Impact of Chemotherapy-Induced Neurotoxicities on Adult Cancer Survivors ' Symptom Burden and Quality of Life." Journal of Cancer Survivorship, 234-245.

Miaskowski, Christine, Steven M. Paul, Judy Mastick, Mark Schumacher, Yvette P. Conley, Betty Smoot, Gary Abrams, et al. 2018. "Hearing Loss and Tinnitus in Survivors with Chemotherapy-Induced Neuropathy." European Journal of Oncology Nursing 32 (July 2017). Elsevier: 1-11. doi:10.1016/j.ejon.2017.10.006.

Miaskowski, Christine, Steven M Paul, Judy Mastick, Gary Abrams, Kimberly Topp, Betty Smoot, Kord M Kober, et al. 2018. "Associations Between Perceived Stress and Chemotherapy-Induced Peripheral Neuropathy and Otoxicity in Adult Cancer Survivors." Journal of Pain and Symptom Management. Elsevier Inc. doi:10.1016/j.jpainsymman.2018.02.021.

Mols, Floortje, Ad J.J.M. Vingerhoets, Jan Willem Coebergh, and Lonneke V. van de PollFranse. 2005. "Quality of Life among Long-Term Breast Cancer Survivors: A Systematic Review." European Journal of Cancer 41 (17). Pergamon: 2613-2619. doi:10.1016/J.EJCA.2005.05.017.

Nondahl, David M., Karen J. Cruickshanks, Dayna S. Dalton, Barbara E.K. Klein, Ronald Klein, Carla R. Schubert, Ted S. Tweed, and Terry L. Wiley. 2007. "The Impact of Tinnitus on Quality of Life in Older Adults." Journal of the American Academy of Audiology 18 (3): 257-266. doi:10.3766/jaaa.18.3.7. 
Nordvik, Øyvind, Peder O. Laugen Heggdal, Jonas Brännström, Flemming Vassbotn, Anne Kari Aarstad, and Hans Jørgen Aarstad. 2018. "Generic Quality of Life in Persons with Hearing Loss: A Systematic Literature Review." BMC Ear, Nose and Throat Disorders 18 (1). BioMed Central: 1. doi:10.1186/s12901-018-0051-6.

Oldenburg, Jan, Sophie D Fossa, Alv A. Dahl, Sophie D. Fosså, and Alv A. Dahl. 2006. "Scale for Chemotherapy-Induced Long-Term Neurotoxicity (SCIN): Psychometrics, Validation, and Findings in a Large Sample of Testicular Cancer Survivors." Quality of Life Research 15 (5): 791-800. doi:10.1007/s11136-005-5370-6.

Oun, Rabbab, Yvonne E. Moussa, and Nial J. Wheate. 2018. "The Side Effects of PlatinumBased Chemotherapy Drugs: A Review for Chemists.” Dalton Transactions 47 (19). The Royal Society of Chemistry: 6645-6653. doi:10.1039/C8DT00838H.

Paken, Jessica, Cyril D. Govender, Mershen Pillay, and Vikash Sewram. 2016. "CisplatinAssociated Ototoxicity: A Review for the Health Professional." Journal of Toxicology 2016. doi:10.1155/2016/1809394.

Saad, Amr Shafik, Ramy R Ghali, and May Ahmed Shawki. 2017. "A Prospective Randomized Controlled Study of Cisplatin versus Carboplatin-Based Regimen in Advanced Squamous Nonsmall Cell Lung Cancer." Journal of Cancer Research and Therapeutics 13 (2). Medknow Publications and Media Pvt. Ltd.: 198-203. doi:10.4103/0973-1482.187287.

Saladin, Shawn P, Robert B Perez, Bianca Cruz PharmD, Yasar Tasnif PharmD, CPM B Robert Perez Bianca Cruz, and PharmD Yasar Tasnif. 2015. "A Review of Ototoxic Medications: Implications for Professionals Working with Consumers with Hearing Loss." Journal of the American Deafness and Rehabilitation Association 49. http://repository.wcsu.edu/jadara.

Siegel, Rebecca L., Kimberly D. Miller, and Ahmedin Jemal. 2018. "Cancer Statistics, 2018." CA: A Cancer Journal for Clinicians 68 (1): 7-30. doi:10.3322/caac.21442.

Skalleberg, Jakob, Olesya Solheim, Sophie D. Fosså, Milada Cvancarova Småstuen, Terje Osnes, Per Ole M. Gundersen, and Marie Bunne. 2017. "Long-Term Ototoxicity in Women after Cisplatin Treatment for Ovarian Germ Cell Cancer." Gynecologic Oncology 145 (1). Elsevier Inc.: 148-153. doi:10.1016/j.ygyno.2017.02.006.

Stein, Kevin D., Karen L. Syrjala, and Michael A. Andrykowski. 2008. "Physical and Psychological Long-Term and Late Effects of Cancer." Cancer 112 (S11). WileyBlackwell: 2577-2592. doi:10.1002/cncr.23448.

"Study Quality Assessment Tools | National Heart, Lung, and Blood Institute (NHLBI)." 2018. Accessed November 1. https://www.nhlbi.nih.gov/health-topics/study-qualityassessment-tools.

Theile, Dirk, and Dirk. 2017. "Under-Reported Aspects of Platinum Drug Pharmacology." Molecules 22 (3). Multidisciplinary Digital Publishing Institute: 382. doi:10.3390/molecules22030382.

Theunissen, Eleonoor A R, Wouter A. Dreschler, Merel N. Latenstein, Coen R N Rasch, Sieberen Van Der Baan, Jan Paul De Boer, Alfons J M Balm, and Charlotte L. Zuur. 2014. "A New Grading System for Ototoxicity in Adults." Annals of Otology, Rhinology and Laryngology 123 (10): 711-718. doi:10.1177/0003489414534010. 
Travis, Lois B., Sophie D. Fossa, Howard D. Sesso, Robert D. Frisina, David N. Herrmann, Clair J. Beard, Darren R. Feldman, et al. 2014. "Chemotherapy-Induced Peripheral Neurotoxicity and Ototoxicity: New Paradigms for Translational Genomics." Journal of the National Cancer Institute 106 (5). doi:10.1093/jnci/dju044.

Tserga, Evangelia, Tara Nandwani, Niklas K. Edvall, Jan Bulla, Poulam Patel, Barbara Canlon, Christopher R. Cederroth, and David M. Baguley. 2019. "The Genetic Vulnerability to Cisplatin Ototoxicity: A Systematic Review.” Scientific Reports 9 (1). Nature Publishing Group: 3455. doi:10.1038/s41598-019-40138-z.

Waissbluth, Sofia, Emilia Peleva, and Sam J. Daniel. 2017. "Platinum-Induced Ototoxicity: A Review of Prevailing Ototoxicity Criteria." European Archives of Oto-RhinoLaryngology 274 (3). Springer Berlin Heidelberg: 1187-1196. doi:10.1007/s00405-0164117-z.

Wells, M., C.J. Semple, and C. Lane. 2015. “A National Survey of Healthcare Professionals' Views on Models of Follow-up, Holistic Needs Assessment and Survivorship Care for Patients with Head and Neck Cancer." European Journal of Cancer Care 24 (6). John Wiley \& Sons, Ltd (10.1111): 873-883. doi:10.1111/ecc.12285.

Wheeler, Heather E., Lois B. Travis, Amy Budnick, Darren Richard Feldman, Lawrence H. Einhorn, Robert James Hamilton, David J. Vaughn, et al. 2015. "Comprehensive Characterization of Cisplatin-Related Hearing Loss in U.S. and Canadian Testicular Cancer Survivors (TCS).” Journal of Clinical Oncology 33 (15_suppl). American Society of Clinical Oncology : 9570-9570. doi:10.1200/jco.2015.33.15_suppl.9570.

Zeman, Florian, Michael Koller, Berthold Langguth, and Michael Landgrebe. 2014. "Which Tinnitus-Related Aspects Are Relevant for Quality of Life and Depression: Results from a Large International Multicentre Sample." Health and Quality of Life Outcomes 12 (1). BioMed Central: 7. doi:10.1186/1477-7525-12-7. 


\begin{tabular}{|c|c|c|c|c|c|c|c|c|}
\hline & Author (year) & Cancer Type & 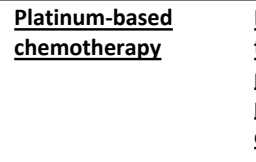 & $\begin{array}{l}\text { Number of patients } \\
\text { total (number of } \\
\text { patients receiving } \\
\text { platinum based } \\
\text { chemotherapy) } \\
\end{array}$ & $\begin{array}{l}\text { Time of evaluation } \\
\text { following } \\
\text { treatment }\end{array}$ & Patient characteristics & $\underline{\text { Control }}$ & Location \\
\hline \multirow{6}{*}{$\begin{array}{l}\text { Cross- } \\
\text { sectional } \\
\text { Studies }\end{array}$} & $\begin{array}{l}\text { Bentzen } \\
\text { (2013) }\end{array}$ & $\begin{array}{l}\text { Squamous cell } \\
\text { carcinoma of } \\
\text { anal region }\end{array}$ & \multicolumn{2}{|c|}{ Cisplatin v non-cisplatin $128(56)$} & $\geq 2$ years & $\begin{array}{l}\text { Patients diagnosed between } 2000-2007 \text { with } \\
\text { curative intent. Those treated with cisplatin } \\
\text { had }>200 \mathrm{mg} / \mathrm{m} 2 \text {. The median time since } \\
\text { diagnosis was } 66 \text { months (range } 25-112 \text { ). }\end{array}$ & $\begin{array}{l}\text { Age/sex matched the participants to } \\
\text { the normal poulation }(n=269) \text {. }\end{array}$ & Norway \\
\hline & $\begin{array}{l}\text { Bokemeyer } \\
\text { (1996) }\end{array}$ & Testicular cancer & \multicolumn{2}{|c|}{$\begin{array}{l}\text { A mixture of different } 90(90) \\
\text { chemotherapy cocktails } \\
\text { containiting cisplatin } \\
\text { (P) :PVB, PEB, PEBVC, } \\
\text { P(high dose)EB, PVB/PE }\end{array}$} & $\begin{array}{l}\text { Median } 58 \text { months } \\
\text { (range } 12-159 \\
\text { months) }\end{array}$ & $\begin{array}{l}\text { Cancer survivors in remission for } 12 \text { months. } \\
\text { The median age of diagnosis was } 28 \text { (range } \\
\text { 19-53). The median follow up was } 53 \text { months } \\
\text { (range } 15 \text { to } 159 \text { ). }\end{array}$ & $\begin{array}{l}\text { Participants grouped in terms of } \\
\text { treatment (PVB, PEB, PEBVc, P(high } \\
\text { dose)EB, PVB/PE) and compared. }\end{array}$ & Germany \\
\hline & $\begin{array}{l}\text { Calhoun } \\
\text { (1998) }\end{array}$ & $\begin{array}{l}\text { Advanced-stage } \\
\text { ovarian cancer }\end{array}$ & $\begin{array}{l}\text { A minimum of } 6 \\
\text { cisplatin cycles }\end{array}$ & $15(15)$ & $\begin{array}{l}\text { Mean } 6.6 \text { years } \\
\text { (range } 2.5-12 \\
\text { years) }\end{array}$ & $\begin{array}{l}\text { Cancer patients with a mean age of } 61.3 \text { years } \\
\text { (range } 44-87 \text { ) who had been living with } \\
\text { cancer for a mean of } 6.6 \text { years (range } 2.5 \text { to } \\
12 \text { years). }\end{array}$ & s Gynaecologic oncologists ( $n=10)$. & USA \\
\hline & \multirow[t]{3}{*}{$\begin{array}{l}\text { Miaskowski } \\
(2018)\end{array}$} & Various & $\begin{array}{l}\text { Platinum based } \\
\text { chemotherapy (PBC) }\end{array}$ & $623(404)$ & $\geq 3$ months & $\begin{array}{l}\text { Cancer survivors treated with PBC } 3+\text { months } \\
\text { from their last cycle and had scale } 3 \text { or above } \\
\text { on CIPN score. } N=623(68.4 \% \text { had CIPN). }\end{array}$ & $\begin{array}{l}\text { Cancer survivors treatedf wih PBC, 3+ } \\
\text { months since last cycle and no } \\
\text { reports in CIN, hearing loss or } \\
\text { tinnitus. }\end{array}$ & San Fracisco, USA \\
\hline & & Various & $\begin{array}{l}\text { Platinum based } \\
\text { chemotherapy (PBC) }\end{array}$ & $623(371)$ & $\geq 3$ months & $\begin{array}{l}\text { Cancer survivors treated with PBC } 3+\text { months } \\
\text { following their last cycle who reported } \\
\text { Hearing loss, Tinnitus and/or CIN }(n=371) \text {. }\end{array}$ & $\begin{array}{l}\text { A comparison of cancer survivors } \\
\text { reporting tinnitus, hearing loss, } \\
\text { hearing loss and CIN, hearing loss } \\
\text { and tinnitus and CIN. }\end{array}$ & San Fracisco, USA \\
\hline & & Various & $\begin{array}{l}\text { Platinum based } \\
\text { chemotherapy (PBC) }\end{array}$ & $623(85)$ & $\geq 3$ months & $\begin{array}{l}\text { Cancer survivors treated with PBC } 3+\text { months } \\
\text { following their last cycle who reported } \\
\text { Hearing loss, Tinnitus and CIN }(n=85) \text {. }\end{array}$ & $\begin{array}{l}\text { Cancer survivors without any signs of } \\
\text { CIN. }\end{array}$ & San Fracisco, USA \\
\hline \multirow[t]{2}{*}{ RCT } & Bezjak (2008) & Earl stage NSCLC & \multirow{2}{*}{$\begin{array}{l}\text { Adjuvant } \\
\text { chemotherapy ( } 4 \text { cycles } \\
\text { of cisplatin and } \\
\text { vinorelbine) vs } \\
\text { observation } \\
\text { Gemcitabine and } \\
\text { carboplatin vs } \\
\text { gemcitabine and } \\
\text { cisplatin }\end{array}$} & $\begin{array}{l}\text { month 0: } 482(242) \text {, } \\
\text { month 36: } 89 \text { (50) }\end{array}$ & $\begin{array}{l}\text { Intervals at } 5,9,12 \\
\text { weeks and at } 6,9 \text {, } \\
1218,24,30 \text {, and } \\
36 \text { months }\end{array}$ & $\begin{array}{l}\text { Cancer patients, } 65 \% \text { male, median } 61 \text { years, } \\
\text { followed up at } 0 \text { and } 36 \text { months following } \\
\text { treatment. }\end{array}$ & $\begin{array}{l}\text { Cancer patients treated with } \\
\text { observation ( } n=240 \text { at month } 0, n=39 \\
\text { at month } 36 \text { ). }\end{array}$ & Canada \\
\hline & Saad (2017) & Stage IV NSCLC & & $\begin{array}{l}71 \text { ( } 36 \text { cisplatin, } 35 \\
\text { carboplatin) }\end{array}$ & $\begin{array}{l}\text { At cycle } 3 \text { and } 6 \text { of } \\
\text { treatment }\end{array}$ & $\begin{array}{l}\text { Patients with stage IV NSCLC excluding grade } \\
3+\text { neuropathy, } 55 \%<55+\text { years and } 77.5 \% \\
\text { male. } 44 \text { patients had multiple sites. }\end{array}$ & $\begin{array}{l}\text { Cancer patients treated with cisplatin } \\
\text { compared to carboplatin. }\end{array}$ & Egypt \\
\hline Longitudinal & Fossa (2003) & $\begin{array}{l}\text { Metastatic } \\
\text { testicular cancer }\end{array}$ & \multicolumn{2}{|c|}{$\begin{array}{l}\text { Cisplatin day } 1 \text { through } 666(666) \\
5 \text { at } 20 \mathrm{mg} / \mathrm{m} 2 \text {. vs } \\
\text { cisplatin days one } \\
\text { through } 3 \text { at } 50 \mathrm{mg} / \mathrm{m} 2 \\
\text { on days one and days } 2 \text {. }\end{array}$} & $\begin{array}{l}\text { Intervals at } 3,6,12 \text {, } \\
\text { and } 24 \text { months }\end{array}$ & $\begin{array}{l}\text { Cancer patients, mean age } 31 \text {, range } 16-63 \text {, } \\
286(52 \%) \text { followed up after } 2 \text { years. }\end{array}$ & $\begin{array}{l}\text { Comparison between cisplatin } \\
\text { regimes. }\end{array}$ & $\begin{array}{l}\text { Norway, The Netherlands, } \\
\text { Rotterdam, UK, Belgium }\end{array}$ \\
\hline \multirow{2}{*}{ Pilot Study } & \multirow[t]{2}{*}{ Fossa (1996) } & $\begin{array}{l}\text { Low-stage } \\
\text { testicular cancer }\end{array}$ & $\begin{array}{l}\text { Surveillance vs } \\
\text { infradiaphragmatic } \\
\text { radiotherapy vs 2-6 } \\
\text { cycles of cisplatin }\end{array}$ & $103(45)$ & $\geq 3$ months & $\begin{array}{l}\text { Disease-free patients who had undergone } \\
\text { treatment, stage } 1 \text { seminoma. }\end{array}$ & $\begin{array}{l}\text { European urologists }(n=20) \text {, } \\
\text { oncologists and radiotherapists } \\
(n=13) \text {. }\end{array}$ & Norway/UK \\
\hline & & $\begin{array}{l}\text { Low-stage } \\
\text { testicular cancer }\end{array}$ & $\begin{array}{l}\text { Surveillance vs } \\
\text { infradiaphragmatic } \\
\text { radiotherapy vs } 2 \text { cycles } \\
\text { of } 100 \mathrm{mg} / \mathrm{m} 2 \text { cisplatin. }\end{array}$ & $206(26)$ & $\geq 3$ months & $\begin{array}{l}107 \text { cancer survivors from Noway and } 99 \\
\text { relapse-free patients from the UK. }\end{array}$ & $\begin{array}{l}\text { Opinions from cancer survivors } \\
\text { compared to opinions from Doctors } \\
(n=10) .\end{array}$ & Norway/UK \\
\hline
\end{tabular}

Table 1 


\begin{tabular}{|c|c|c|c|c|c|c|c|c|c|c|c|}
\hline \multirow{2}{*}{$\begin{array}{l}\text { Author (year) } \\
\text { Quality analysis }\end{array}$} & \multirow{2}{*}{$\begin{array}{l}\text { Bentzen (2013) } \\
7 / 14\end{array}$} & \multirow{2}{*}{$\begin{array}{l}\text { Bokemeyer } \\
\text { (1996) }\end{array}$} & \multirow{2}{*}{$\begin{array}{l}\text { Calhoun (1998) } \\
7 / 14\end{array}$} & \multicolumn{3}{|c|}{ Miaskowski (2018) } & \multirow{2}{*}{$\begin{array}{l}\text { Bezjak (2008) } \\
11 / 14\end{array}$} & \multirow{2}{*}{$\begin{array}{l}\text { Saad } \\
\text { (2017) } \\
9 / 14\end{array}$} & \multirow{2}{*}{$\begin{array}{l}\begin{array}{l}\text { Fossa } \\
\text { (2003) }\end{array} \\
12 / 14\end{array}$} & \multicolumn{2}{|c|}{ Fossa (1996) } \\
\hline & & & & $10 / 14$ & $10 / 14$ & $9 / 14$ & & & & $3 / 14$ & $3 / 14$ \\
\hline & $50.00 \%$ & $64.29 \%$ & $50.00 \%$ & $71.43 \%$ & $71.43 \%$ & $64.29 \%$ & $78.57 \%$ & $64.29 \%$ & $85.71 \%$ & $21.43 \%$ & $21.43 \%$ \\
\hline
\end{tabular}

Table 2 

interviews with

\section{Calhoun (1998) To evaluate issues None} related to chemotherapy-induced toxicities in women and compare it to oncologists answers on a survey. QoL outcomes in cancer questionnaire: I have questionnaire: I survivors with CIPN and ringing or buzzing in have trouble no CIPN. my ears, scored from hearing, scored

To identify hearing loss FACT/GOG-Ntx FACT/GOG-Ntx and tinnitus in survivors questionnaire: I have questionnaire: I with chemotherapy- ringing or buzzing in have trouble induced neuropathy. my ears, scored from hearing, scored from 0-4

To identify the impact of FACT/GOG-Ntx FACT/GOG-NtX tom burden questionnaire: I get questionnaire: and QoL. ringing or buzzing in have trouble my ears scored from hearing score from $0-4$

\section{Utlity score Utility score comparing symptoms to None with ototoxicity 1 (good health) and 0 (death)}

\section{Other}

structured

questions

Blood samples, $18(21 \%)$ patients had persisting ototoxicity, $8(95 \%)$ patients had transient ototoxicity and 60 Medical histories, (70\%) patients had no ototoxicity. There were 86 audiograms performed showing $31(36 \%)$ physical examination, patient complaints

None

(1)

None

$A$

QoL-PV, SF-12, CES-D scale LFS fatigue None scale, sleep disturbance GSDS, Attentional functional index Al, stress PSS and IES-R questionnaires i.e: During the past 4 weeks, how much of the time has your physical health or emotional problems interfered wit your social activities (like visiting friends, relatives, etc.)?

QoL-PV, SF-12, CES-D scale LFS fatigue None scale, sleep disturbance GSDS, Attentional functional index Al, stress PSS and IES-R questionnaires i.e: During the past 4 weeks, how much of the time has your physical health or emotional problems interfered with your social activities (like visitin friends, relatives, etc.)?

QoL-PV, SF-12, CES-D scale LFS fatigue None scale, sleep disturbance GSDS, Attentional functional index Al, stress PSS and IES-R questionnaires: During the past 4 weeks, how much of the time has your physical health or emotional problems interfered with your social activities (like visi
friends, relatives, etc.)?

\section{Results}

There were more smokers in cancer survivors than in the control population, survivors also had worse QoL scores overall and in single items, the most significant being fatigue. Global QoL was non-significant patients with chemotherapy-induced hearing loss. However it was only possible to exclusively evaluate 45 of the 86 audiograms due to others having confounding hearing issues. Every patient which a cumulative dose of $650 \mathrm{mg} / \mathrm{m} 2$ complained of persisting ototoxicity. There was a threefold increased risk for ototoxicity in patients with a history of noise exposure. Those with high dose of cisplatin had significantly worse QoL than those with lose dose, and those with persisting toxicities reported a worse QoL The PEB and High CDP + cisplatin regimens results in significantly increased late toxicities.

A total of 8 women had experienced at least mild ototoxicity. Patients scored ototoxicity as 0.92 and oncologists as 0.69 in the utility questionnaire. Patients who had experienced toxicities assigned a higher utility score for toxicities, especially those they'd personally experienced. It was concluded that patients tolerated toxicities in the face of maintaining stable disease. Physicians

CIPN survivors statistically had a higher BMI, a higher SCQ score, a lower KPS score and were born prematurely. Only 613 survivors completed the hearing loss item and from these, $34.5 \%$ reporte hearing loss (score 1+). These survivors were significantly older, had a higher SCQ score, a lower KS score, more likely to be male and had a higher IES-R score. Only 609 survivors completed the tinnitus item, out of these, 31\% reported tinnitus. Statistically, they had less education, a higher SCQ score, were more likely to be male, were more likely to have had platinum based ough the IES-R core didn't reach the cut-off for PTSD in this population, their scores are comparable to those with R. Arthritis.

Those who had CIN/HL/TIN were statistically more likely to be male from a lower economic background with no childcare responsibilities. They also experienced a more severe hearing loss than those in the other subgroups, had a lower KPs score, more likely to have clinical depression, had a higher dose and more cycles of cisplatin, had a significantly increase in anxiety, experienced lower morning energy, lower attention function scores and lower QoL. Those with only CIN/HL were more likely to be older, have a higher anxiety score, but no difference in stress (IES-R or PSS score) and no difference in spiritual wellbeing.

From the 609 survivors, $68.9 \%$ had $\mathrm{CIN}$ and $31.4 \%$ did not have $\mathrm{CIN}$. Those with all HL/TIN/CIN were significantly older, more likely to be unemployed, had a lower annual household income with no child care responsibilities, a higher BMI, a higher number of comorbidities, a lower KPS score, had received fewer cancer treatments, had more back pain, were more likely to have clinical depression and kidney disease and didn't exercise. This population also had a significantly lower QoL with every specific item addressed on the questionnaire other than spiritual wellbeing. were less favourable.

\section{Table 3}




\begin{tabular}{|c|c|c|c|c|c|c|c|}
\hline Bezjak (2008) & $\begin{array}{l}\text { To identify the QoL } \\
\text { outcome in an analysis } \\
\text { of a RCT. }\end{array}$ & None & $\begin{array}{l}15 \text { items from } \mathrm{NClC} \\
\text { CTG questionnaire: } \\
\text { loss of hearing } \\
\text { scored from } 0-4\end{array}$ & & $\begin{array}{l}\text { EORTC QLQ-C30 questionnaire: How } \\
\text { would you rate your overall quality of } \\
\text { life during the past week? }\end{array}$ & None & $\begin{array}{l}\text { Those treated with chemotherapy had significantly worse fatigue, lower appetite, hair loss and } \\
\text { vomiting which all subsided. There was no difference in QoL overall, but statistically significant } \\
\text { worse hearing loss in chemotherapy group ( }(=0.03) \text { which was deemed permanent at } 12 \text { months. } \\
\text { A higher QoL correlated with longer survival, and the only persistent symptoms reported in this } \\
\text { study were neurotoxicity and ototoxicity in the chemotherapy group. }\end{array}$ \\
\hline Saad (2017) & $\begin{array}{l}\text { To compare the two } \\
\text { treatment regimens in } \\
\text { terms of toxicities and } \\
\text { QoL. }\end{array}$ & None & None & $\begin{array}{l}\text { NCI-CTCAE } \\
\text { grading system, } \\
\text { however is not } \\
\text { clear }\end{array}$ & $\begin{array}{l}\text { FACT-L and TOI questionnaires: I am } \\
\text { content with the quality of my life } \\
\text { right now scored from 0-4 }\end{array}$ & None & $\begin{array}{l}\text { Rates of ototoxicity were significant higher in Gem/Cis group. Ototoxicity was reported in } 9 \\
\text { patients (25\%) in the cisplatin group at Grade 1, and no ototoxicity was reported in the carbplatin } \\
\text { group. }\end{array}$ \\
\hline Fossa (2003) & $\begin{array}{l}\text { To describe QoL in } \\
\text { metastatic testicular } \\
\text { cancer patients treated } \\
\text { with cisplatin. }\end{array}$ & None & None & TC Module & $\begin{array}{l}\text { EORTC QLQ-C30 questionnaire: How } \\
\text { would you rate your overall quality of } \\
\text { life during the past week? }\end{array}$ & None & $\begin{array}{l}\text { A total of } 42(6 \%) \text { patients stopped chemotherapy due to ototoxicity. Tinnitus was higher in those } \\
\text { treated with the } 4 \text { cycles and } 3 \text { day regimen at all time points and overall. A mean of } 4.9 \text { had } \\
\text { tinnitus at baseline, with } 5 \% \text { improving, } 69 \% \text { who had no change and } 26 \% \text { worsened. A mean of } 3.1 \\
\text { had hearing loss at baseline, with } 3 \% \text { improving, } 76 \% \text { experienced no change and } 21 \% \text { had } \\
\text { worsening of symptoms. At } 6 \text { months the group receiving the } 4 \text { cycles and } 3 \text { day regimen had } \\
\text { worse hearing loss. Long term ototoxicity was reported by } 20-25 \% \text { of patients. Tinnitus occured in } \\
50 \% \text { of patients and hearing loss for speech frequencies in } 10 \% \text { and for high frequency in } 60 \% \text { of } \\
\text { patients. }\end{array}$ \\
\hline \multirow[t]{2}{*}{ Fossa (1996) } & $\begin{array}{l}\text { To identify long-term } \\
\text { somatic and } \\
\text { pyscological morbidity } \\
\text { in patients and compare } \\
\text { this with opinions from } \\
\text { doctors on QoL. }\end{array}$ & None & $\begin{array}{l}\text { Non-validated } \\
\text { qustionnaire with } \\
15 \text { items. } \\
\text { Ototoxicity: } \\
\text { impaired hearing }\end{array}$ & $\begin{array}{l}\text { Non-validated } \\
\text { qustionnaire } \\
\text { with } 15 \text { items. } \\
\text { Ototoxicity: } \\
\text { impaired } \\
\text { hearing }\end{array}$ & $\begin{array}{l}\text { Non-validated qustionnaire with } 15 \\
\text { items including QoL issues }\end{array}$ & $\begin{array}{l}\text { Rank significance } \\
\text { of indicated } \\
\text { physical and } \\
\text { psychosocial } \\
\text { dimension in } \\
\text { hypothetical } \\
\text { scenarios }\end{array}$ & $\begin{array}{l}\text { The overall satisfaction with the health-care provision was reported as the most relevant QoL item } \\
\text { from the patients point of view, however this was not recognised by the doctors. Ototoxicity was } \\
\text { scored by patients as } 2.7 \text { (SD 2.1) and by the doctors, } 4.7 \text { (SD 1.6) (of a score from } 1 \text { to } 7 \text { ). }\end{array}$ \\
\hline & $\begin{array}{l}\text { To dentify long-term } \\
\text { somatic and } \\
\text { pyscological morbidity } \\
\text { in patients and compare } \\
\text { this with opinions from } \\
\text { doctors on QoL. }\end{array}$ & None & None & $\begin{array}{l}\text { Non-validated } \\
\text { questionnaire } \\
\text { with } 18 \text { items. } \\
\text { have you } \\
\text { suffered from } \\
\text { reduced } \\
\text { hearing/ringing } \\
\text { in the ears? }\end{array}$ & $\begin{array}{l}\text { Non-validated qustionnaire with } 18 \\
\text { items including QoL issues }\end{array}$ & None & $\begin{array}{l}\text { Reduced hearing and tinnitus was scored } 1.3 \text { (SD } 0.72 \text { ) by the patients and } 1.4 \text { (SD } 0.66 \text { ) by the } \\
\text { doctors on a scale of } 1 \text { to } 7 \text {. }\end{array}$ \\
\hline
\end{tabular}

\section{Table 3 continued}




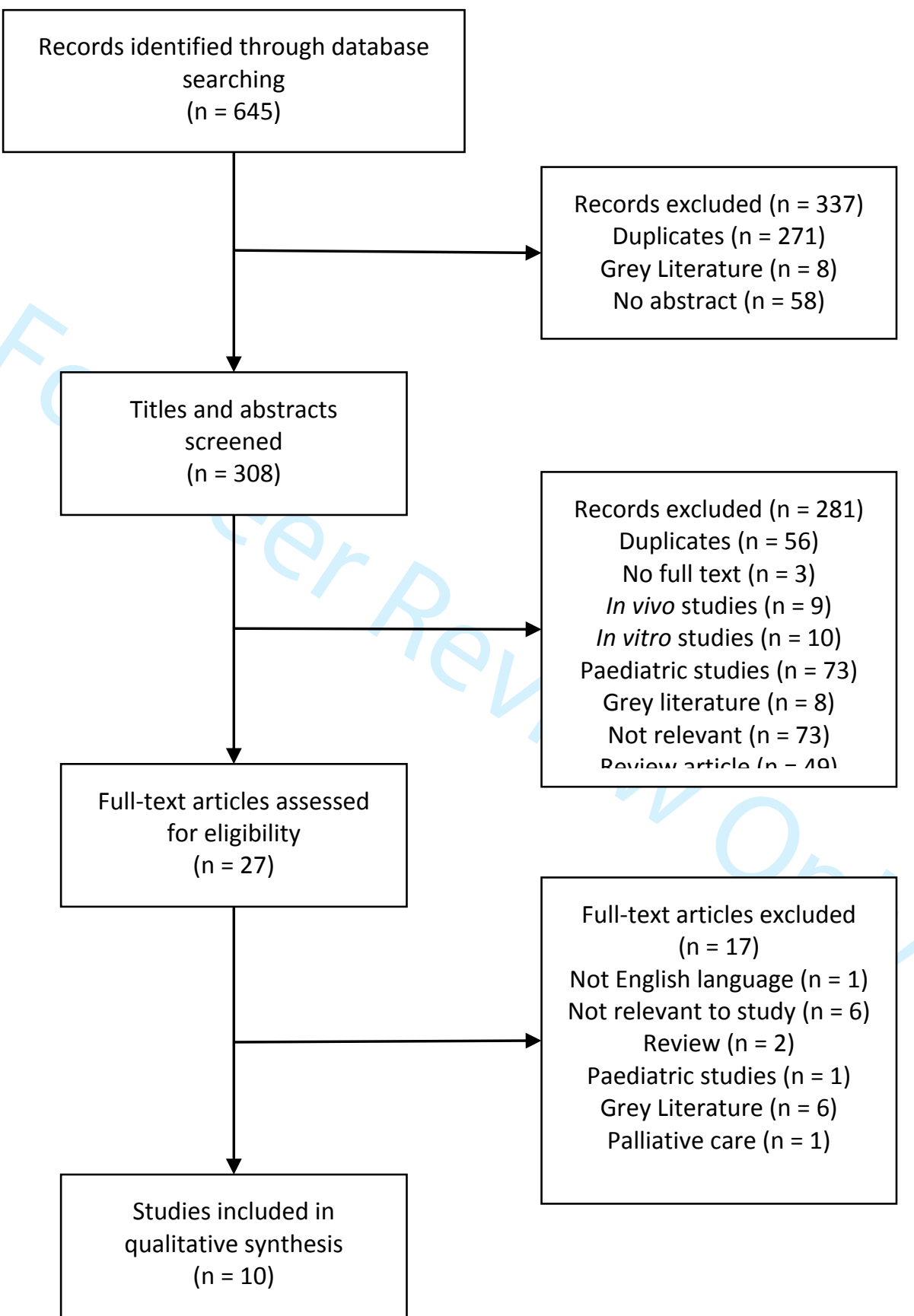

E-mail:editor.ija@up.ac.za URL: http://mc.manuscriptcentral.com/tija 